This report was prepared as an account of work sponsored by the United States Government. Neither the United States nor the United States Atomic Energy Commission, nor any of their employees, nor any of their contractors, subcontractors, or their employees, makes any warranty, express or inplied, or assumes any legal liability or responsibility for the accuracy, completeness or usefulness of any information, apparatus, product or process disclosed, or represents that its use would not infringe privately owned rights.

In the interest of prompt distribution, this LAMS report was not edited by the Technical Information staff.

Printed in the United States of America. Available from National Technical Information Service

U. S. Department of Commerce

5285 Port Royal Road

Springfield, Virginia 22151

Price: Printed Copy $\$$ Microfiche $\$ 0.95$

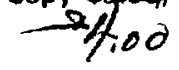




\author{
LA-5255-MS \\ Informal Report \\ UC. 25 \\ ISSUED: May 1973
}

\title{
Initial Development and Characterization of Plutonia-Iridium Cermets (PIC)
}

by

M. Tokar

M. W. Shupe

R. A. Kent

R. W. Zocher

T. K. Keenan

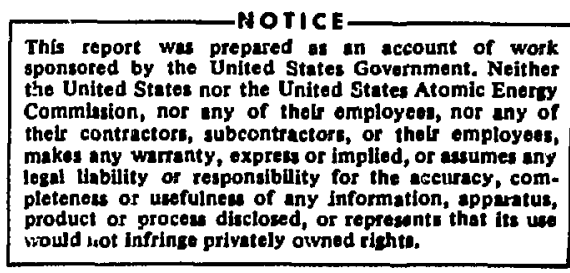

Work supported by the Division of Spaci Nuclear Systems, USAEC 


\section{CONTENTS}

I. INTRODUCTION + . . . . . . . . . . . . . . . . 1

I. METHOD OF APPROACH . . . . . . . . . . . . . . . . . 2

III. MATERLALS ACQUISITION AND PREPARATION . . . . . . . . . 2

A. Iridium Preparation and Characterization . . . . . . . . . 2

B. Plutonia Powder Preparation and Characterization . . . . . . 3

C. Preparation of Plutonia Granules . . . . . . . . . . . . 4

D. Cam-Coating . . . . . . . . . . . . . . . . . 4

E. Mixing of $\mathrm{PuO}_{2}$ and Ir . . . . . . . . . . . . . . . . 4

F. Preparation and Loading of Graphite Dies. . . . . . . . . 5

G. Hot Pressing . . . . . . . . . . . . . . . . 5

IV. PROCESSING RESULTS AND DISCUSSION . . . . . . . . . . . . . . 6

A. Relationship of Microstructure and Density to . . . . . . . . 6 Process Parameters and Feed

1. General Comments . . . . . . . . . . . . 6

2. Fresh Savannah River Oxide (SRO) vs. Recycle Feed . . . 7

3. $\mathrm{PuO}_{2}$ Granule Size Distribution and Ir Content. . . . . . . 8

4. Ceramic Particle Coating . . . . . . . . . . . . . 9

B. Stoichiometry and Heat Treatment . . . . . . . . . . . s

C. PIC Sphere... . . . . . . . . . . . . . . . . 15

V. ASYMMETRICAL THERMAL RAMP OF PIC SPHERE $\quad$ • . . . . . 16

A. Ramp Experimental . . . . . . . . . . . . . . 16

B. Theoretical Considerations, . . . . . . . . . . . 17

VI. Diametral Compression Tests . . . . . . . . . . . . . 17

VII Summary . . . . . . . . . . . . . . . . . . . 20 
INITLAL DEVELOPMENT AND CHARACTERIZATION OF PLUTONLA-IRIDIUM CERMETS

(PIC)

by

M. Tokar, M.W. Shupe, R. A. Kent

R.W. Zocher, T. K. Keenan

\begin{abstract}
An investigation of a Plutonia-Iridium Cermet (PIC; as a candidate radio-isotopic fuel has been initiated at the Los Alamos Scientific Laboratory. Specimens containing 11 to 15 vol\% iridium as a continuous phase have been prepared by a multi-step process which includes (1) granulation and prefiring of ${ }^{238} \mathrm{Pu}^{16} \mathrm{O}_{2}$ to provide a ceramic phase having a selected size distribution usually ranging from 61 to $297 \mu$, (2) comminution of -325 mesh Ir powder to $s 5 \mu$ particles, (3) coating or mixing the ceramic granules with the metallic particles, (4) hot pressing the mixture in vacuum, and (5) adjustment of the stoichivinetry of the oxide by heat treatment in a suitable atmosphere. The resultant microstructures consist of islands of ${ }^{238} \mathrm{Pu}^{16} \mathrm{O}_{2}$ surrounded by a continuous Ir coating approximately 2 to $5 \mu$ thick. Several small pellets, nominally $\doteq .3$ in. diameter, have been prepared as well as a 1.5 in. diameter sphere with a ${ }^{208} \mathrm{Pu}$ thermai inventory of 100 watts. The pellets were used for process development, fractography, chemical analyses, metallography. strength measurements, etc. The sphere was fabricated to verify piccess up-scaling from the pellet development. It was subjected to some thermal testing.
\end{abstract}

\section{INTRODUCTION}

The purpose of any radioisotopic heat source is to produce heat for eventual convexsion into electrical power. Usable power is then employed in various devices which operate in locations on the earth's surface or in space where more conventional power sources are not effective over long periocis of time. The compound ${ }^{258} \mathrm{PuO}_{2}$ has been frequently used as a source of heat for these purposes. Taking tnto account the amount of ${ }^{258} \mathrm{Pu}$ actually present in the compound, coupled with the 87.8 year half-life and the determined alpha energies, there is avallable $\sim 0.4$ watt $/ \mathrm{g}{ }^{258} \mathrm{PuO}_{2}$.
This material is currently employed in two forms hy the Space Nuclear Systems Division of the USAEC. One form is a plutonia molybdenum cermet (PMS) disk approximately 2 in. diameter and 0.2 in. thick. From the specifled ${ }^{258} \mathrm{Pu}$ content, each disk carries a 40 watt ( $\left.t\right)$ inventory. Stacks of these disks are encapsulated in suitable materials to form the working heut source. The second fuel form currently in use is spherical in shape, 1. $465 \mathrm{in}$. diam, and consists only of ${ }^{238} \mathrm{PuO}_{2}$. This fuel form is called pure plutonium oxide (PPO). Each fuel ophere is separately encapsulated and arrays of encapsulated spheres are then combined to form the heat source. 
Each of the above forms has inherent advantages and disadvantages. The PMC disks have higher thermal conductivity and thermal shock resistance due to the metallic phase. However, disk fabrication requires more elaborate processing and controls because of the multiphase system. Molybdenum is somewhat susceptible to oxidation. The PPO spheres, although lower in conductivity and thermal shock resistance, are fabricated by a much more simple process. Since they are separately encapsulated in Ir, manipulative techniques are not as demanding as with stacks of disks.

The Los Alamos Scientific Laboratory has been assigned the role of advanced fuel form development by the Space Nuclear Systems Division of the USAEC. Therefore, a program was initiated to explore the formation and preliminary characterization of a plutonium iridium cermet. Such a form could combine the best features of PMC and PPO; that is, maintaining the high thermal conductivity and thermal shock resistant qualities of a cermet while substituting the more chemically inert iridium for molybdenumi in the metallic phase.

This report describes the conceptual phases of that developmental study. Enough data have been accrued to demonstrate fabrication feasibility and initial characterization. Future studies will augment the properties evaluations so that prudent choices can be made for more advanced heat sources.

\section{METHOD OF APPROACH}

The preliminary fabrication procedures were dictated by the rusultant microstructure of the cermets. A homogeneous dispersion of iridium particles in a ${ }^{298} \mathrm{Pu}^{16} \mathrm{O}_{2}$ ceramic matrix was not desired. Instead, the microstructure was to consist of relatively large granules of ceramic surrounied by a continuous network of iridium. This microstructure was considered to have Beveral advantages: (1) It provides a path for the reloase of helium generated from the decay of the plutonlum.

(2) A continuous metallic phase would have improved thermal properties compared to one consisting of isoIated metal particlea in a coramic matrix. (3) The envelopment of the $\mathrm{PuO}_{2}$ by oxidation and corrosionresistant Ir would have beneficial aspects in a re-entry situation.

To achieve the desired microstructure, it was necessary to prepare ceramic granules in an app=opriate size range by prefiring cold-pressed agglomerates of $\mathrm{PuO}_{2}$ powder, to coat the fired $\mathrm{PuO}_{2}$ granules with Ir powder, and finally to hot press the mixture. A direct cold press and sinter approach was considered but the many unknown variables madc hot pressing the favored choice for the initial study. By simultaneously pressing 3 small pellets there was sufficiont material to permit adequate prochuct characterization and process variable evaluation. After establishing the desired conditions, the process was scaled-up to produce a 100-watt sphere. The following section describe:- in detail the procedure used to prepare the plutonia ir dium cermets.

III. MATERLALS ACQUISITION AND PREPARATION A. Iridium Preparation and Characterization The iridium was received* as $99.5 \%$ purity, -325 mesh powder. Spectrochemical data on this powder in the es-received condition are provided in Table $I$. Small batches of powder ( $15 \mathrm{~g}$ ) were slurried with ethyl alcohol in a tungsten carbide-lined osch' 'fory mill ** and were ground with tungsten carbide balls. The proportions used were $15 \mathrm{~g} \mathrm{Ir}, 15 \mathrm{ml} \mathrm{C}_{2} \mathrm{H}_{5} \mathrm{OH}$, and 200 WC balls, each $0.5 \mathrm{~cm}$ diam. Milling time was approximately 2 hours per batch.

After the milling, the powder was dried and Bcreened in a Sonic Sifter, *** The material $>5 \mu \mathrm{m}$ in size was resycled, whereas the smaller particles were used in the cermet preparation. Spectrochemical analyois of the comminuted powder indicated some tungsten plck-up occurred. Other milling materials (such as $\mathrm{UO}_{2}$ ) are being considered to eliminate this problem.

\footnotetext{
* Source: Englehard Incustries, 429 Dolaney Street, Newark, Now Jersey 17105

* Pulverit Comminution Equipment (made in Cermany by Alfred Fritsch Ohg Laborgeraeterbau 658 Idar-Ohersteln 1).

* * Allen-Bradley Model L3P Pulse Type Sonic Slfter, Milwaukee, Wisconsin.
} 
TABLE I

\section{SPECTROCHEMICAL ANALYSIS OF}

\section{AS-RECEIVED IRIDIUM POWDER}

(ppm by weight)

\begin{tabular}{|c|c|c|c|}
\hline $\mathbf{L i}$ & $<10$ & $\mathbf{N i}$ & $<30$ \\
\hline $\mathrm{Be}$ & $<3$ & $\mathrm{Cu}$ & $<$ \\
\hline B & $<10$ & $\mathrm{Zn}$ & $<\mathbf{3 0 0}$ \\
\hline $\mathrm{Na}$ & $<30$ & $\mathrm{Sr}$ & $<30$ \\
\hline $\mathbf{M g}$ & $<3$ & $\mathrm{Zr}$ & $<100$ \\
\hline $\mathrm{Al}$ & $<100$ & $\mathrm{Nb}$ & 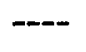 \\
\hline $\mathbf{S i}$ & 20 & Mo & $<300$ \\
\hline $\mathrm{Ca}$ & 3 & Cd & $<100$ \\
\hline V & $<10$ & Sn & $<100$ \\
\hline $\mathrm{Cr}$ & $<30$ & $\mathbf{T a}$ & $<400$ \\
\hline Mn & $<3$ & $\mathbf{W}$ & $<200$ \\
\hline $\mathrm{Fe}$ & 100 & $\mathrm{~Pb}$ & 100 \\
\hline Co & $<30$ & $\mathbf{B i}$ & $<30$ \\
\hline
\end{tabular}

TABLE II

TYPICAL CHEMICAL AND SPECTROCHEMICAL ANALYSES OT MILLED AND $\mathrm{O}^{16}$ - EXCHANGED PLUTONIA POWDER

\begin{tabular}{|c|c|c|c|c|}
\hline $\mathbf{P u}$ & 87.8 & (wt. \%) & Min & 2 (ppm) \\
\hline Th & 0.10 & (wt.\%) & $\mathbf{F e}$ & 70 (ppm) \\
\hline 0 & 11.85 & (wt.\%) & Co & 5 (ppm) \\
\hline $\mathbf{A m}$ & 0.127 & (wt.\%) & $\mathbf{N i}$ & 10 (ppm) \\
\hline Np & 0.226 & (wt.\%) & $\mathrm{Cu}$ & $<\quad 2(\mathrm{ppm})$ \\
\hline${ }^{234} \mathrm{U}$ & 1.165 & (wt. \%) & $\mathrm{Zn}$ & $<10(\mathrm{ppm})$ \\
\hline C & 45 & (ppm) & $\mathbf{S r}$ & $<10(\mathrm{ppm})$ \\
\hline${ }^{236} \mathrm{Pu}$ & 0.63 & (ppm) & Mo & $<100(\mathrm{ppm})$ \\
\hline $\mathbf{L i}$ & $<$ & (ppm) & Cd & $<20(\mathrm{ppm})$ \\
\hline $\mathbf{B e}$ & $<$ & (ppm) & Sn & $5(\mathrm{ppm})$ \\
\hline $\mathbf{B}$ & $<$ & (ppm) & $\mathrm{Pb}$ & 15 (ppm) \\
\hline $\mathrm{Na}$ & 50 & (ppm) & $\mathrm{Bi}$ & 1 (ppm) \\
\hline $\mathbf{M g}$ & 15 & (ppm) & $\mathbf{K}$ & 15 (ppm) \\
\hline Al & 10 & (ppm) & $\mathbf{T i}$ & $<50(\mathrm{ppm})$ \\
\hline $\mathrm{Si}$ & 30 & (ppm) & $\mathbf{R b}$ & 4 (ppm) \\
\hline $\mathrm{Ca}$ & 150 & (ppm) & $\mathbf{Y}$ & $4(\mathrm{ppm})$ \\
\hline $\mathrm{Cr}$ & 15 & $(\mathrm{ppm})$ & $\mathbf{B a}$ & 20 (ppm) \\
\hline
\end{tabular}

B. Plutonia Powder Preparation and Characterization

The plutonia was received from the Savannah

River Laboratory. The as-received material, nominally 7 to $8 \mu$. was ${ }^{16} \mathrm{O}$ exchanged by heating to $750^{\circ} \mathrm{C}$ for 96 hours in an $\mathrm{H}_{2}{ }^{16} \mathrm{O}-\mathrm{Ar}$ atmosphere. The ${ }^{16} \mathrm{O}$ exchanged material was outgassed at $1000^{\circ} \mathrm{C}$ for 1 hour in the same atmosphere. The ${ }^{16} \mathrm{O}$ exchanged and outgassed powder was ball-milled for 16 hours in $80 \mathrm{~g}$ batches. The material was milled dry at 20 RPM in stainless steel mills.

Particle size analysis of the milled powder yielded a mass median diameter granule of $2_{-0.6}^{+1} u$. A typical chemical analysis of the milled powder is provided in Tabie II.

Recycled oxide provided a second source of $\mathrm{PuO}_{2}$

feed. This recycled feed was obtained from various PPO spheres which had been originally hot-pressed at $1480^{\circ} \mathrm{C}$ and had been fabricated during the PPO development program. They were broken, crushed in the oscillatory mill, outgassed and ball-milled for 42 hrs raiker than $16 \mathrm{hrs}$. With this exception. the feed treatments were identical. The particle sizes and chemical analyses of this material were not significantly different from the fresh oxide.

\section{Preparation of Plutonia Granules}

The exchanged and milled $\mathrm{PuO}_{2}$ powder was ready for granulation to a selected size range. The $\mathrm{PuO}_{2}$ powder was dry pressed in hardened steel dies at 50 tsi. The reisultant pellets were broken manually and passed through a stack of screens to provide granules in the desired size range (for example, 105 to $295 u$ ). Material passing through the fine mesh screen was recycled.

The cold pressed, green granules were firc, at temperatures from 1075 to $1350^{\circ} \mathrm{C}$ in $\mathrm{CO}_{2}$ for 2 hor : 9 . This fired granular material was again screened. Table III shows a spectrochemical analysis of a typical lot of prefired gr'anules.

Various size ranges of granules were used as feed material for the hot rressed pellets, but the recommended range from these studies is $61-295 \mu$. Some actual aize distributiong are provided in Table IV. A ollghtly higher percentage of fines was obtained from the recycled feed powdor due to its previous thermal history and more friable nature. 
TABLE III

SPECTROCHEMICAL ANALYSIS OF A TYPICAL BATCH OF PLUTONIA GRANULES

AFTER PREFIRING

\begin{tabular}{|c|c|c|c|}
\hline Element & ppm & Element & ppm \\
\hline Al & 70 & Mn & 8 \\
\hline B & $<$ & Mo & 2 \\
\hline $\mathrm{Ba}$ & 4 & $\mathrm{Na}$ & 50 \\
\hline $\mathrm{Be}$ & $<$ & $\mathrm{Ni}$ & 60 \\
\hline $\mathrm{Bi}$ & $:$ & $\mathrm{Pb}$ & $<$ \\
\hline $\mathrm{Ca}$ & 100 & $\mathrm{Rb}$ & $<$ \\
\hline Cd & 10 & $\operatorname{Re}$ & $<$ \\
\hline Co & $<$ & $\mathbf{S i}$ & 250 \\
\hline $\mathrm{Cr}$ & 120 & Sn & $<$ \\
\hline Cs & 20 & $\mathbf{S r}$ & $\mathbf{5}$ \\
\hline $\mathbf{C u}$ & $<$ & $\mathrm{Ta}$ & $<1000$ \\
\hline $\mathrm{Fe}$ & 400 & $\mathbf{T i}$ & 15 \\
\hline Hf & $<$ & V & $<$ \\
\hline $\mathbf{K}$ & 20 & $\mathbf{w}$ & 50 \\
\hline $\mathbf{L a}$ & $<$ & $\mathbf{Y}$ & $<$ \\
\hline $\mathbf{L i}$ & $<$ & $\mathrm{Zn}$ & 20 \\
\hline Mg & 25 & $\mathbf{Z r}$ & $<$ \\
\hline
\end{tabular}

TABLE TV

SIZE DISTRIBUTION OF PREFIRED PLUTONIA GRANULES*

\begin{tabular}{|c|c|c|c|}
\hline \multirow[b]{2}{*}{ Size $(\mu)$} & \multicolumn{3}{|c|}{ Peruent in Final Batch No. } \\
\hline & PGT-3C & PGT-4A & PGT-5 \\
\hline $246-295$ & 8.56 & 19.12 & 18.3 \\
\hline $208-246$ & 18.29 & 22.63 & 21.3 \\
\hline $175-208$ & 13.23 & 14.45 & 16.1 \\
\hline $149-175$ & 15.18 & 11.68 & 12.2 \\
\hline $125-149$ & 14.40 & 9.93 & 10.6 \\
\hline $104-125$ & 12.06 & 8.76 & 8.4 \\
\hline $74-104$ & 16.34 & 13.28 & 12.7 \\
\hline $61-74$ & 1.94 & 0.15 & 0.4 \\
\hline Reject $(-61$ & $19.84 \%$ & $2.14 \%$ & $2.50 \%$ \\
\hline
\end{tabular}

PGT-3C $=$ Recycle oxtde, fired at $1075^{\circ} \mathrm{C}$ in $\mathrm{CO}_{2}$ for $2 \mathrm{hrs}$ PGT-4A = Freeh oxide, fired at $1075^{\circ} \mathrm{C}$ in $\mathrm{CO}_{2}$ for $2 \mathrm{hrs}$ PGT-5 = Fresh oxide, flred at $1075^{\circ} \mathrm{C}$ in $\mathrm{CO}_{2}$ for 2 hrs

*AB determined by screening.

\section{Cam-Coating}

Earlier work on $\mathrm{ThO}_{2}$-Mo cermets at the Evendale, Ohio ${ }^{(1)}$ facility of the General Electric Company established that the desired microstructure could be achieved by creating an initial electrostatic attraction between the metal and ceramic particles. The metallic particles, having a different surface charge than the ceramic granules, would tend to coat the ceramic, and on subsequent pressing, the desired microstructure would be 'Tocked in". Investigators at G. E. believed that this could be attained by a process called "cam-coating" wherein a thin coating of camphor was applied to the metallic powder. Metal powder particles were slurried with a 3.4 $\mathrm{w} / \%$ solution of camphor in acetone in the proportion of $10 \mathrm{~g}$ powder to $2.8 \mathrm{ml}$ of solution. These proportions were reported fairly critical.

In the present work, the Ir to be coated was placed in a $50 \mathrm{ml}$ beaker with the camphor-acetone solution. The beaker was placed in an ultrasonic cleaner and agitated for 2 to 3 minutes until the contents were thoroughly mixed. The slurry was then dried to a cake at $\leq 40^{\circ} \mathrm{C}$. The dried cake was broken in a blender (G. E. - Evendale stated this was an essential part of the procedure to produce an electrostatic charge on the metal particles). After removing the powder from the blender, the material was screened through a $20 \mu$ screen in the Sonic Sifter and was stored.

Although this procedure was followed without deviation during the initial phases of this investigation, there was incentive to simplify this step. The presence of organic materials as camphor/acetone in combination with thermally warm $\mathrm{PuO}_{2}$ is not a desirable situation. Therefore, cam-coating was eliminated in later runs, and comparison or the product microstructures indicated no significant differences. This will be discussed in more detail in a later section.

E. Mixing of $\mathrm{PuO}_{2}$ and Ir

The desired quantity of ${ }^{238} \mathrm{Pu}^{16} \mathrm{O}_{2}$ granules was s.pread evenly over the bottom of a glass Petrie dish. After placing a 325 mesh screen over the dish, the iridium was sprinkled onto the screen and the entire system was vibrated to sift the $\mathrm{Ir}$ onto the $\mathrm{PuO}_{2}$. The combined 
powders were mixed by oscillation for 10 minutes in the glass dish.

Because of the self-heating of ${ }^{288} \mathrm{PuO}_{2}$, the $\mathrm{Ir}-\mathrm{PuO}_{2}$ mixtures were restricted to $\sim 10 \mathrm{~g}$ batches. The reasons for this were two-fold: (1) To decrease the loss of camphor during the early studies, and (2) to maintain as homogeneous a mixture as possible.

\section{F. Preparation and Loading of Graphite Dies}

Stackpole A331 and POCO AXF graphite were used for the hot press dies and punches. The A331 dies were used for the early runs, but their relatively low strength limited pressures to $4000-6000$ psí. POXO AXF die material allowed pressures up to $10,000 \mathrm{psi}$.

In the first fourteen runs the material was loaded into a bare die cavity. However, subsequent metallography indicated the plutonia had been slightly rectuced indicating interaction with the die carbonaceous material. In subsequent pressings, the die cavities and inner punch faces were coated with Ir prior to loading by painting the graphite with a slurry of $s 5 \mu$ Ir sud alcohol and drying the parts at $\sim 100^{\circ} \mathrm{C}$. During hot pressing, the painted Ir powder adhered to and became part of the hot pressed piece leaving the graphite ourface Ir-free.

Except for PIC-20 and $\mathrm{PIC-2I}$ the $\mathrm{Ir}-\mathrm{PuO}_{2}$ charge was initially cold-pressed at a pressure equal to the subsequent hot press pressure.

\section{G. Hot Pressing}

The major portion of the process development involved the hot pressing of 0.3 in. diam $\times 0.3$ in. long pellets. The final step in this phase of this investigation was the successful fabrication of a $11 / 2 \mathrm{in.} \mathrm{diam} \mathrm{sphere.}$ The types of dies and punches used in hot pressing these shapes are shown in Fig. 1. Three pellete ware pressed simultaneously in a small vacurum furnace powered by a $15 \mathrm{kw}, 10 \mathrm{kHz}$ MG. The 3-hole graphite dle was the eusceptor as well as the material container. The PTC Bpuere was hot pressed in a lerger vacuum furnace powered by a $100 \mathrm{kw}, 10 \mathrm{kHz} \mathrm{MG}$. In both cases, the initial vacuum was $\sim 1 \times 10^{-6}$ Torr, the pressure rising to $\sim 1 \times 10^{-4}$ Torr as the temperature was raised.

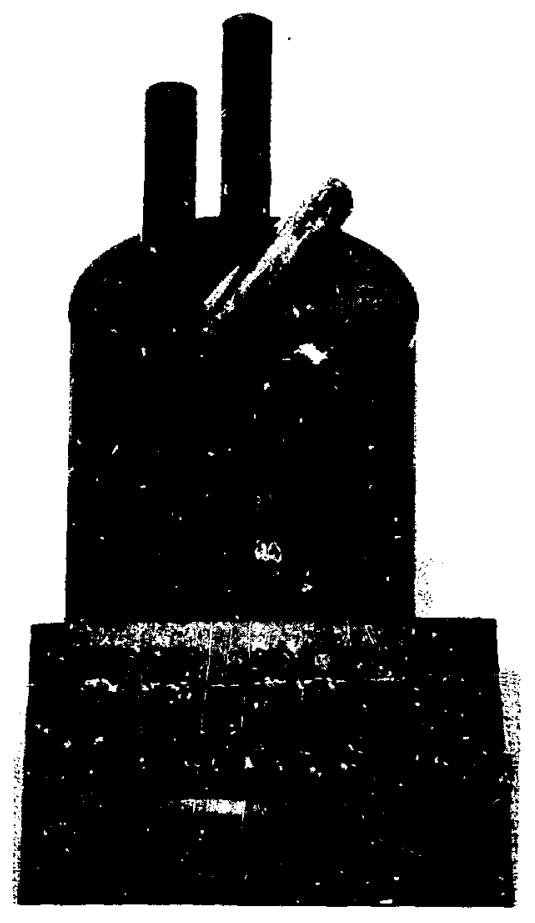

Flg. 1a. Die and punch assembly for ymall PIC specimens.

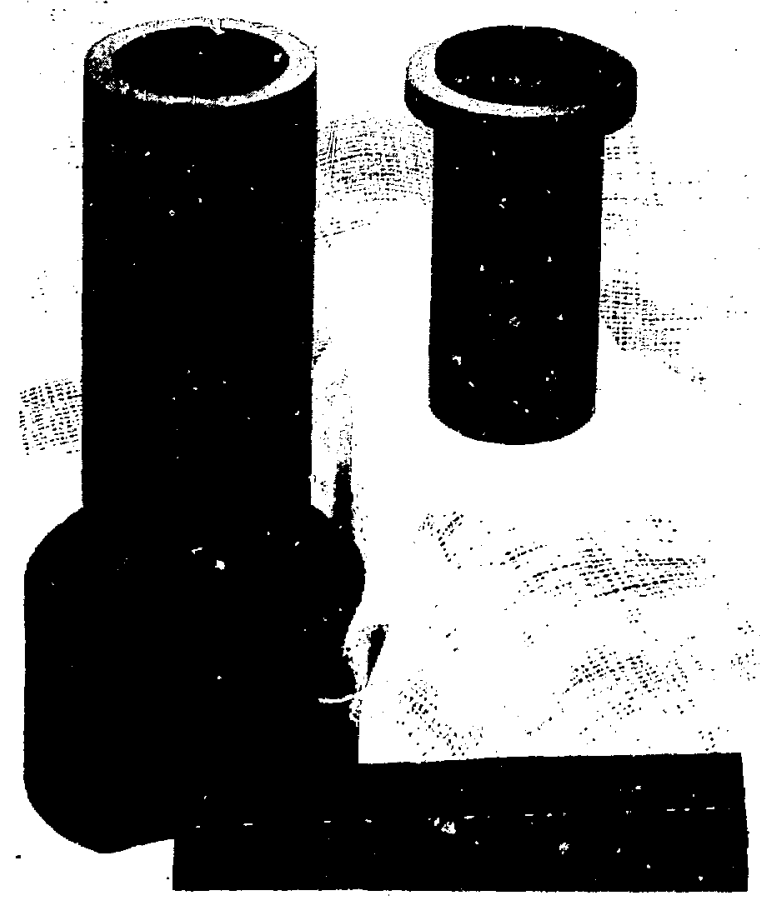

Fig. 2b. Die and punch assembly for 100 watt PIC spheres. 


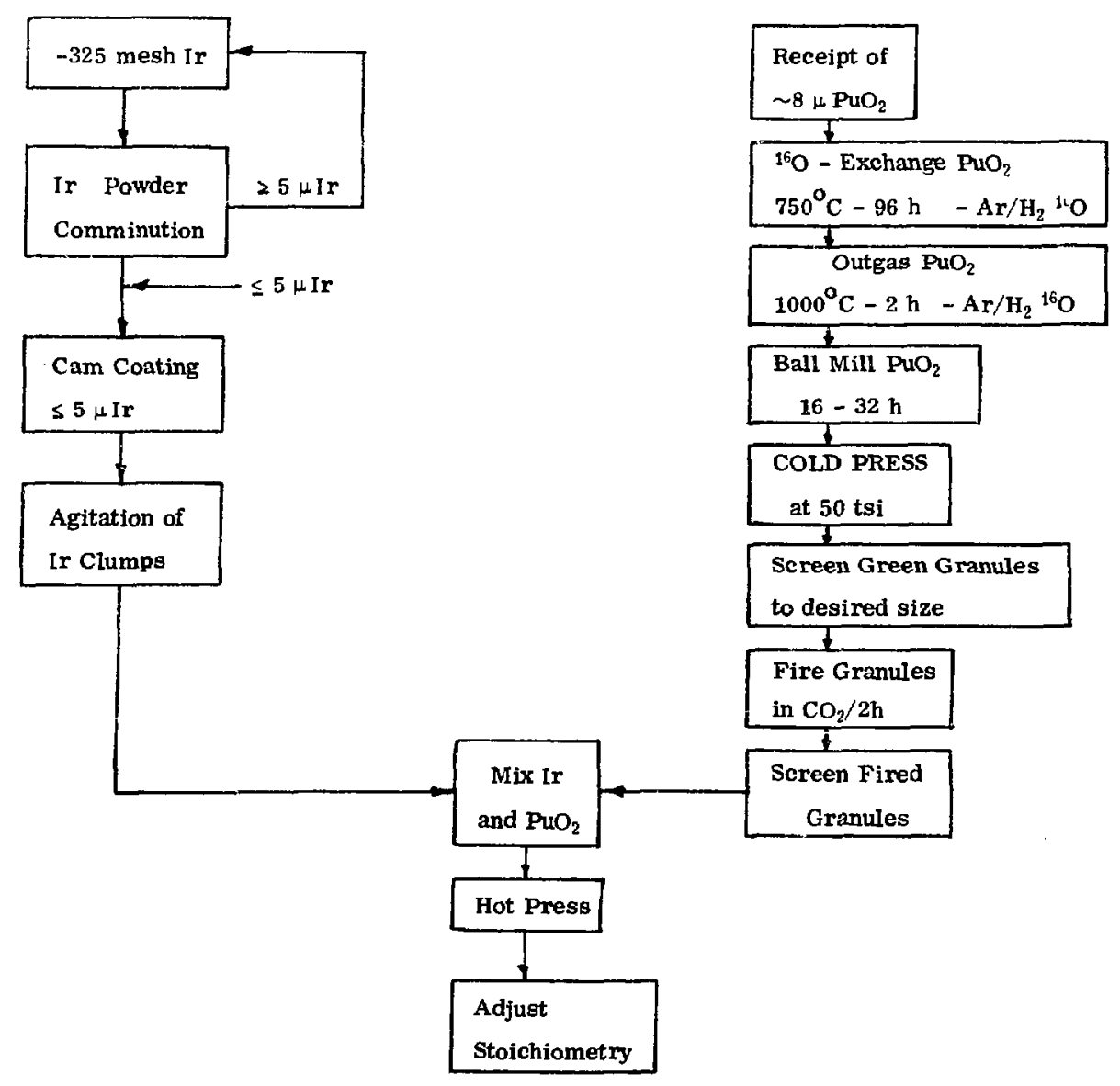

Process Flow Chart for Fabrication of Plutonium-Iridium Cermets

Fig. 2. Flow chart for PIC specimen preparation.

Pressure was applied hydraulically. Except for PIC, -20 and 21 (the PIC sphere) the pressure was applied prior to heat-up of the charge and was released before starting cool-down. With PIC-20 and 21, the pressure was applied at temperature. It was necessary that this latter procechure be used with the sphere fabrication because applying full pressure initially could have caused punch knife-edge fracture.

The hot-presging parameters of interest included the pressure, masimum temperature, and soak time. Typically, the temperature was raised as quickly as possible so that the soak temperature (read optically through a black-body hole in the susceptor) was reaches in 3 to 4 minutes. The time interval from pressure release to motor-generator shut-down was approximately 1/2 hour.

A summary flow sheet for the materials preparation and fabrication processes is given in Fig. 2.

\section{PROCESSING RESULTS AND DISCUSSION}

A. Relationship of Microstructure and Density to Process Parameters and Feed

1. General Comments - The cermet specimens were evaluated primarily by microstructure. 
Microstructural variables of interest included:

(a) porosity; amount, shape, and distzibution (b) Ir distribution; integrity and homogeneity around the $\mathrm{FuO}_{2}$ granules (c) stoichiometry of the oxide. The assessment of the relative worth of a processing method and the zelection of a particular value for a process parameter depended upon the effect of that parameter on one or more of these microstructural variables.

Density was the easiest microstructure-related property to measure since it could be determined either mechanically, by pycnometry, or ceramographically. The effects of $\mathrm{PuO}_{2}$ granule prefiring temperature, granule size distribution, hot pressing parameters, Ir content, and type of $\mathrm{PuO}_{2}$ powder feed on the density were of special interest because of the desirability of achieving high ceramic densities with uniform composition. The major processing variables and their effect on density are summarized in Table V. As expected, the relative density (expressed as percent of theoretical) generally increased with increasing temperature, pressure, soak time and decreasing $\mathrm{PuO}_{2}$ granule prefiring temperature. For example, the PIC-2 pellets prepared from high-fired $\left(1320^{\circ} \mathrm{C}\right)$ granules and pressed at a relatively low pressure (2000 psi) averaged $\sim 81 \%$ T.D. compdred to the PIC-19 pellets (hot pressed at 10,000 psi from $1075^{\circ} \mathrm{C}$ fired $\mathrm{PuO}_{2}$ granules) at $96 \%$ T. D. A more precise determination of single variables on resultant density must await further investigation. However, it seems wellestablished that the $\mathrm{PuO}_{2}$ granule prefire temperature be approximately $1075^{\circ}$ to $1150^{\circ} \mathrm{C}$. Granules prefired at $21320^{\circ} \mathrm{C}$ were quite resistant to further sintering as evidenced by the relatively low density of the PIC-2 and PIC-3 pellets.

2. Fresh Savannah River Oxide (SRO) vs. Recycle Feed - As discussed in section III of this report, two sources of $\mathrm{PuO}_{2}$ powder were used as feed granules: (1) "fresh" Savanwah River Oxide (SRO) which had been ${ }^{16} \mathrm{O}$ exchanged and ball milled 16 hours, aud (2) "recycle" feed which was recovered from PPO speoimens by crushing and ball milling for 42 hours. PIC pellets prepared from these powders, however, did not have equivalent microstructures, as demonstrated in Fig. 3. The oxide granules (in the PIC-9 pellet) prepared from the "fresh" feed had less intragranular porosity. Moreover, the Ir coating for the pellet prepared from "recycle" feed (PIC-14 HT) contained a much greater proportion of $\mathrm{PuO}_{2}$ "fines".

Both the PIC-9 pellet and the PIC-14 HT pellet were prepared from granules prefired at $1075^{\circ} \mathrm{C}$. The recycle feed powder, however, is apparently much less reactive (sinterable) than the fresh feed powder even though they are nominally the same size. The individual grains which comprise large granules are probably not well-bonded in the case of recycled material prefired at $1075^{\circ} \mathrm{C}$. When $\mathrm{PuO}_{2}$ and $\mathrm{Ir}$ are mixed together, the friable granules tend to disintegrate along the edges and $\mathrm{PuO}_{2}$ "fines" are interspersed with the Ir coating. Raising the prefire temperature produces a more unsinterable particle, and thus is more difficult to press to desirable density levels. That approach to minimize interspersed fines appears unfruitful.

It should be pointed out that the microstructure shown in Fig. 3b, while not as esthetically pleasing as that produced from fresh oxide, has not been demonstrated definitely undesirable from the standpoint of strength, He release, thermal shock resistance, etc. The interspersed $\mathrm{PuO}_{2}$ fines in the Ir could act as a strengthening agent at high temperatures. The greater number of intragranular pores could act as crack-propagation arresters and these effects could result in bodios having greater thermal shock resistance than those prepared from fresh material.

The difference in hot pressing behavior of the two feed materials is illustrated in Fig. 4, which shows slump gauge readings as a function of time for PIC-19 (fresh feed) and PIC-17 (recycle) under identical conditions; e.g. same pressing temperature and pressure, feed granule size distribution, prefire temperature, and Ir content (see Table V). The PIC-19 pellets averaged about $96 \%$ T. D., however, while the PIC-17 pellets were only 91\% dense. The data show that the PIC-19 charge started to siump rapidly at about $1.25 \mathrm{~min}$. (coinciding with a temperature of $\sim 1185^{\circ} \mathrm{C}$ ) with most of the slump (> 0.10 in.) occurring in about one more minute. Total 


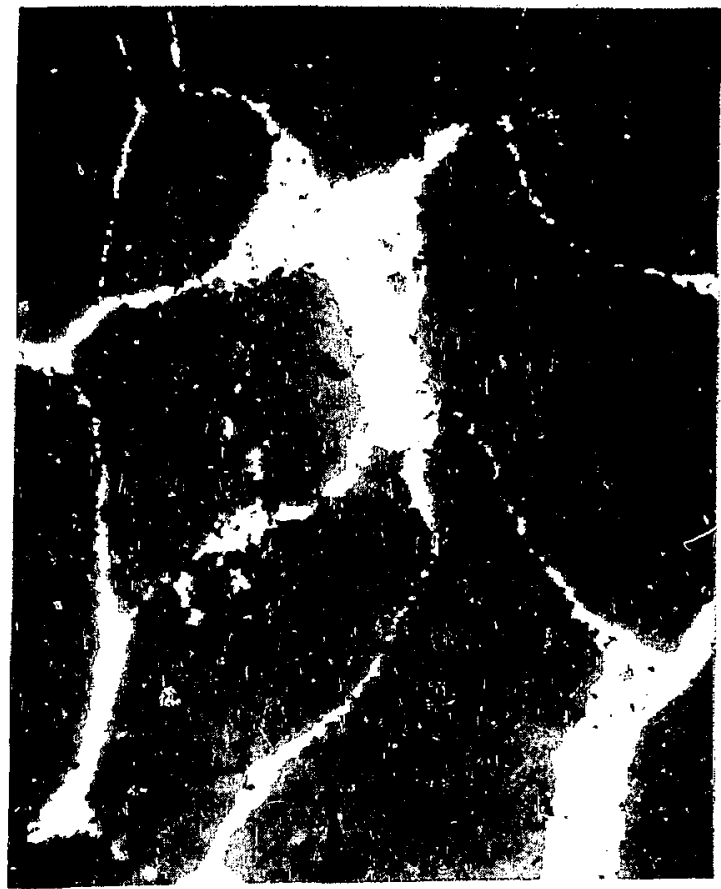

$|20 \mu|$

a) PIC-9 hot pressed from "fresh" Savannah River Oxide.

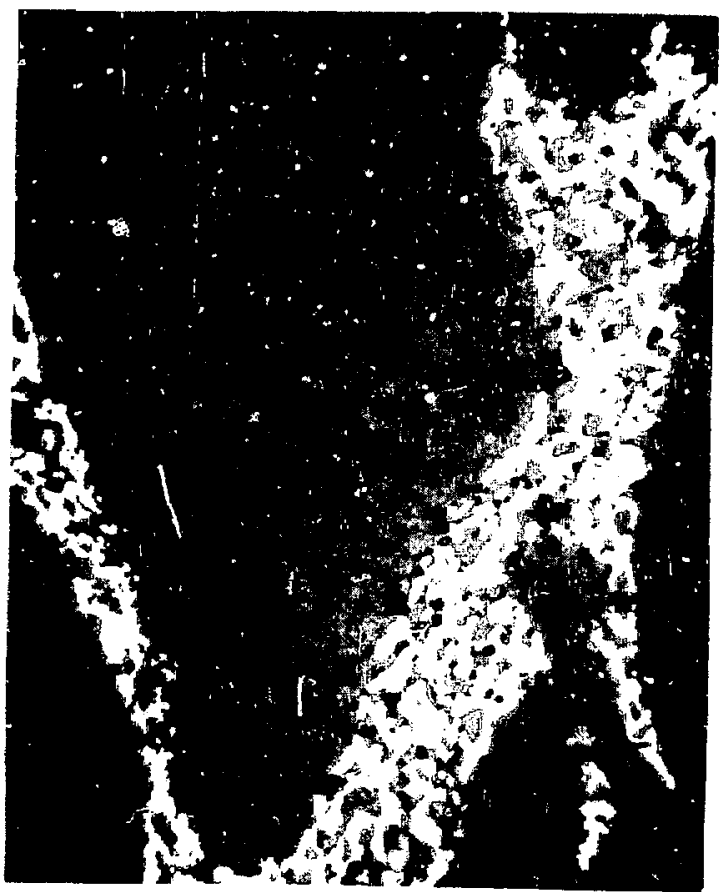

$20 \mu$

As Polished

b) PIC-14HT hot pressed from recycled oxide.

Fig. 3 Effect of oxide feed on microstructure

slump was $\sim 0.115$ in. The PIC-17 charge started to slump at $\sim 1.75 \mathrm{~min}$. (at approximately the same temperature) but the slumping rate was lower, and the total slump was 0.054 in. The difference in sinterability of the granules produced from the two feeds cannot at this time be ascribed to a single cause. Better characterization of the powders by electron microscopy and surface area measurements should yield more quantitative information.

3. $\mathrm{PuO}_{2}$ Granule Size Distribution and Ir ContentAs stated in section III-D, the amount of iridium required to achieve a desired microstructure is directly related to the $\mathrm{PuO}_{2}$ granule size distribution because of surface area relationships. The specific surface or surface area per unit of mass would be valuable data for calculating the quantity of Ir required to coat a given mass of $\mathrm{PuO}_{2}$ granules. The specific surface could have been computed if the granules were in the shape of regular solids, but since they were irregular, the Ir content and granule size distribution were varied on a trial and error basis and were evaluated by ceramography.

Except for PIC-12 the cermets contained either 12 or 15 vol\% Ir. Typical $\mathrm{PuO}_{2}$ granule size distributions used with 12 vol\% are provided in Table IV. Batch number PGT-4A, for example, was used to prepare the PIC-19 pellets, and a photomacrograph and photomicrograph are shown in Fig. 5. 'the Ir was reasonably well distributed throughout the pellet. Using the processing procecture described previously (in section III-E) it was not possible to achieve an Ir coating completely uniform In thickness as shown in Fig. 5b. The adequacy of such a coating must await further testing.

It should be noted from Fig. 5 that the $\mathrm{PuO}_{2}$ granules tended to be flattened with respect to the pressing direction. Evidence of substantial plastic flow can be seen in lower magnification photomacrograph Fig. 5a). 
PIC PROCESSING DATA

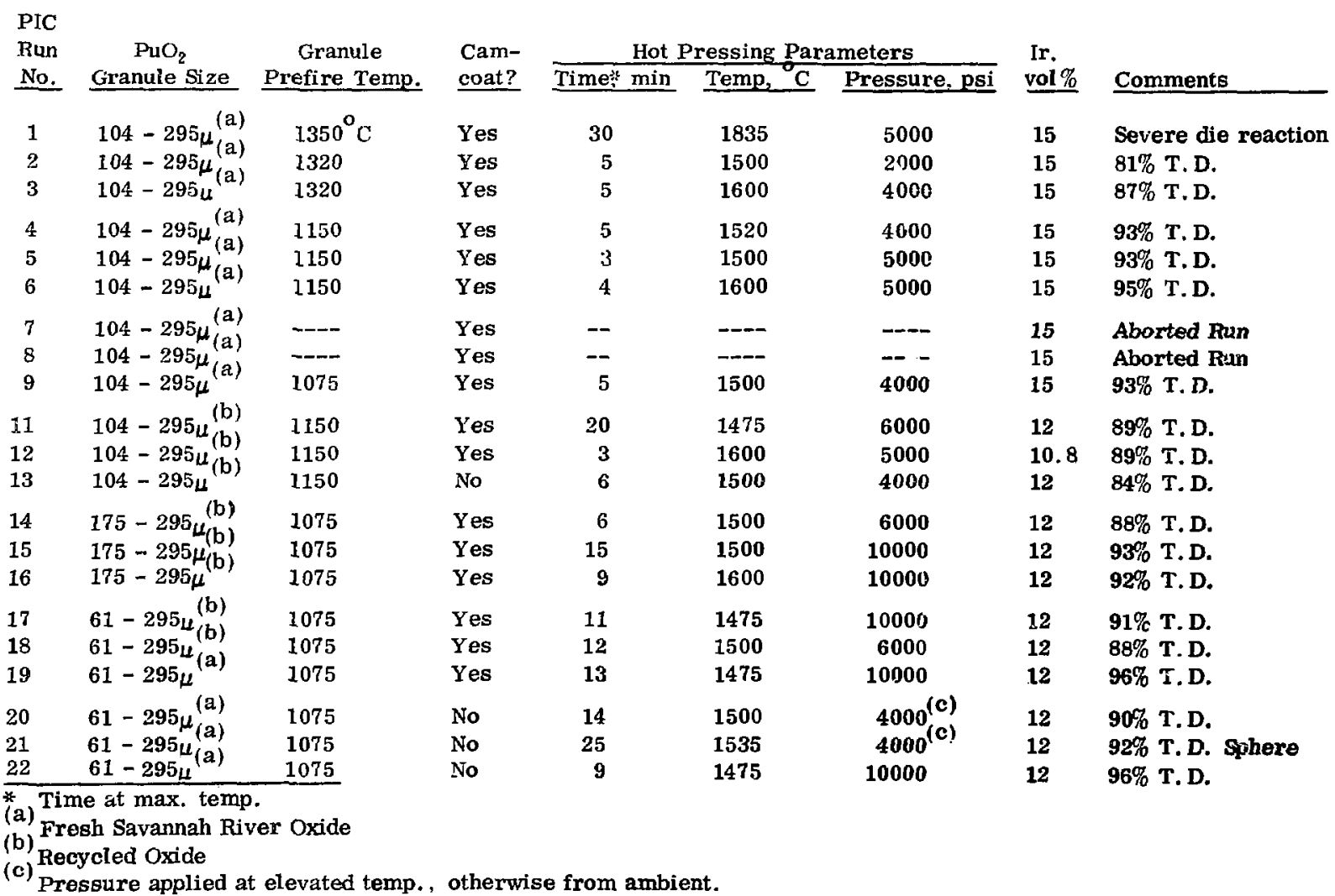

This is due to the $1075^{\circ} \mathrm{C}$ prefiring temperature used for the $\mathrm{PuO}_{2}$ granules and the high pressure $(10,000 \mathrm{psi})$ used. These PIC-19 pellets had the highest relative density and tine highest strength of all fabrications.

4. Ceramic Particle Coating - The cam coating process employed during the early stages of this investigation did not prove necessary to form cermets of alequate microstructure. It appears, therefore, that the coating of the $\mathrm{PuO}_{2}$ gramules by the Ir occurs as a result of a combination of two factors. First, the Ir powder particles are aitracted to the $\mathrm{PuO}_{2}$ gramules cue to a surface static electric charge on the granules. Plutonium dioxide, as a ceramic insulator and dielectric will tend to acquire and retain a surface charge from the surround- ings. The iridium powder particles will also become charged in a similar fashion. Metallic Iridium is a relatively good conductor and would lose its charge more readily with a resultant net difference between the two phases. A second contributing factor to the coating phenomenon could be equally significant. The emaller Ir particles assume a packing distribution in the interstices of the larger $\mathrm{PuO}_{2}$ gramules thereby creating a microstructure of large $\mathrm{PuO}_{2}$ Islands surrounded by Ir.

\section{B. Stolchlometry and Heat Treatment}

The microstructure of the PIC pellets invariably contained some plutonium sesquioxide, $\mathrm{PuO}_{1 \cdot 6}$. This resulted from the hot pressing conditions of high temperature, pressure, and varuum in graphite dies. Thus, 


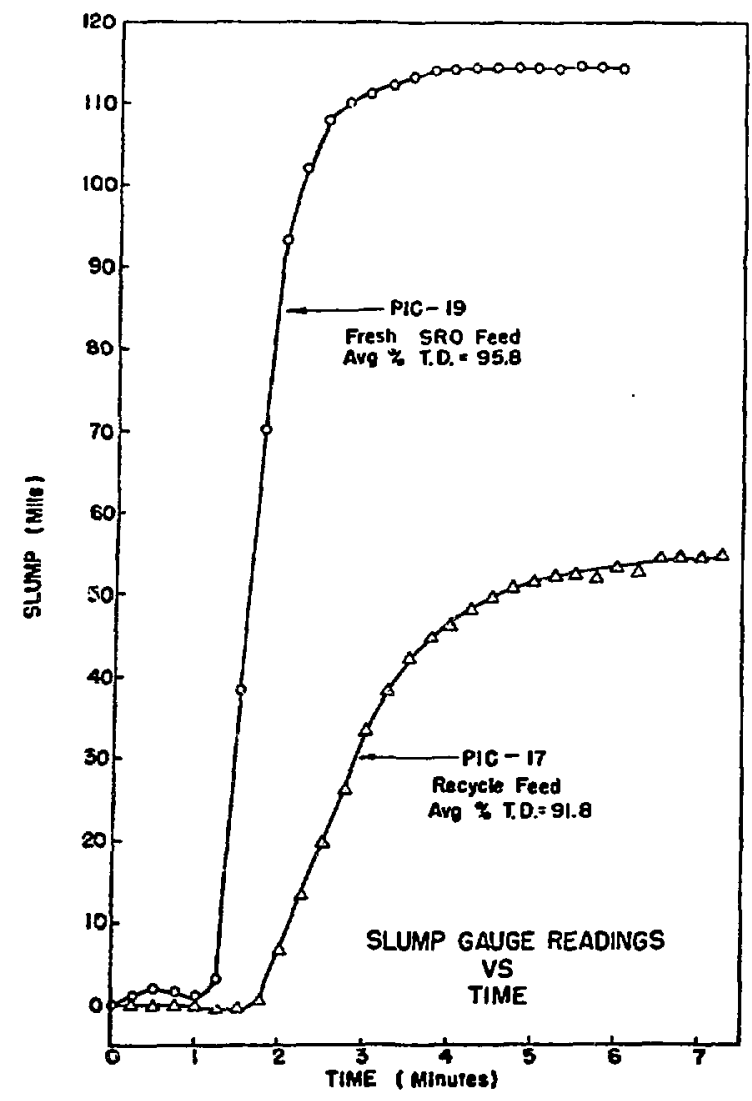

Fig. 4 Effect of feed history on slump gauge readings.

the pellets contained three parases: Ir metal, $\mathrm{PuO}_{2 \cdot 00}$, and $\mathrm{PuO}_{1.6}$ in varfing amounts depending on the processing conditions. Reduction of the dloxdde to sesquioxdde appeared to accelerate rapidly as the hot press temperature was raised above $1500^{\circ} \mathrm{C}$. This can be fllustrated by comparing Fig. 6a with Fig. 7a, which show the aspressed microstructures of pellet PIC-4 $\left(1520^{\circ} \mathrm{C}\right)$ and pellet PIC-3 $\left(1600^{\circ} \mathrm{C}\right)$. It is evident that the pellet PIC-3 sontained a substantfally greater amount of Besquioxide. It is interesting to note the moxphology of the sesquioxide in the pellet PIC-4 indicates a continuous Interfactal layer of $\mathrm{PuO}_{1 \cdot 8}$ between the Ir and $\mathrm{PuO}_{2}$. Either the $\mathrm{PuO}_{\mathrm{f} \cdot 00}$ is reduced by the Ir (whlch seems unlikely), or there is an enhanced diffusion path between the Ir and the ceramic which leads to a reduction on the surface of the ceramic granules. There might be a surface diffusion of oxygen atoms away from the metal-ceramic interface to the specimen surface. If this mechanism does exist, it could also be a positive factor in $\mathrm{He}$ release, since the He atoms could follow the same path.

To determine how the microstructure, stoichiometry, and density of the PIC specimens might change under various environments, a few pellets were subjected to varying heat treatments. The heat treatment conditions and results are summarized in Table VI.

According to the literature ${ }^{(2-4)}$, iridium may form a volatile oxide at temperatures above $1100^{\circ} \mathrm{C}$. The first heat treatment, therefore, was performed on a PIC-3 and a PIC-4 pellet which were heated to $1100^{\circ} \mathrm{C}$ in air for 41 hours. The microstructure of the heattreated PIC-4 pellet is shown in Fig. 6b. The eesquioxide was oxidized to $\mathrm{PuO}_{2}$ whereas the Ir was relatively unaffected. A similar situation was encountered with the PIC-3 pellet (Fig. 7b). In the latter case, however, several micrseracks are evident. These cracks probably result from stresses which are created in the structure by the change in volume as $\mathrm{PuO}_{1.6}$ is reconverted to $\mathrm{PuO}_{2}$. The PIC-4 pellet had been pressed at $1520^{\circ} \mathrm{C}$ comparod to $1600^{\circ} \mathrm{C}$ for PIC-3. It appears desirable, to limit the hot pressing temperature to some values near $1500^{\circ} \mathrm{C}$ to prevent excessive reduction of the plutonia.

As shown in Table VI, both the PIC-3HT and PIC-4HT pellets lost weight as a result of the heat treatment; they also underwent some shrinkage. Two factore enter into the weight changes caused by these heat treatments. If an oxdizing atmosphere is employed, Bome of the iridium may be oxidized and the weight of the body decreases. Countering this, however, is the weight gain caused by the reoxidation of the substoichiometric oxdde to $\mathrm{PuO}_{2 \cdot 00}$. The net weight change is the resultant of these two effects. Changes in overall density involve both the weight change plus any dimensional changes due to sintering. For example, it is evident from Table VI that the density of the pellet PIC-3HT Increased slightly whereas the pellet PIC-4HT underwent a s.light density decrease. Pellet PIC-3HT however, 


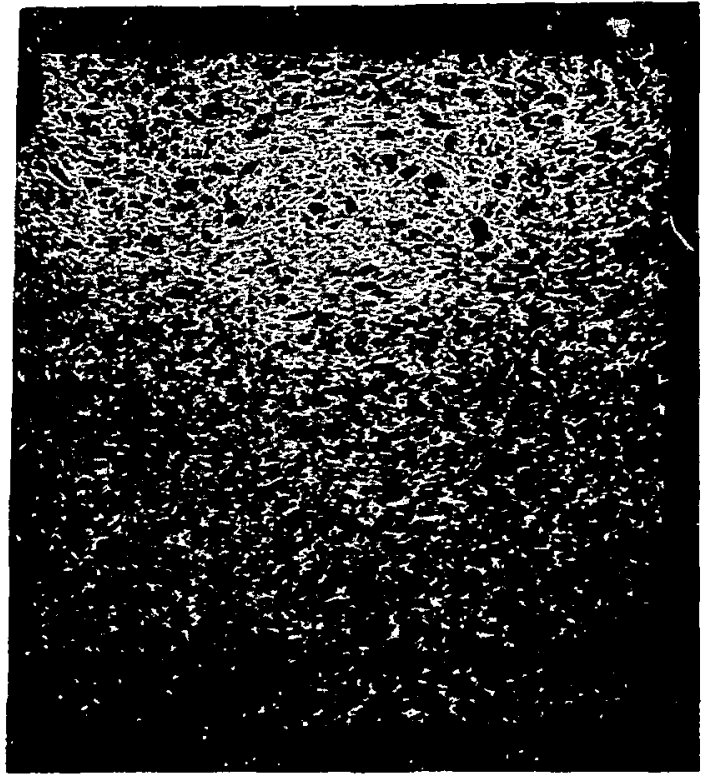

$|1000 \mu|$

a) PIC-19 pellet cross-section.

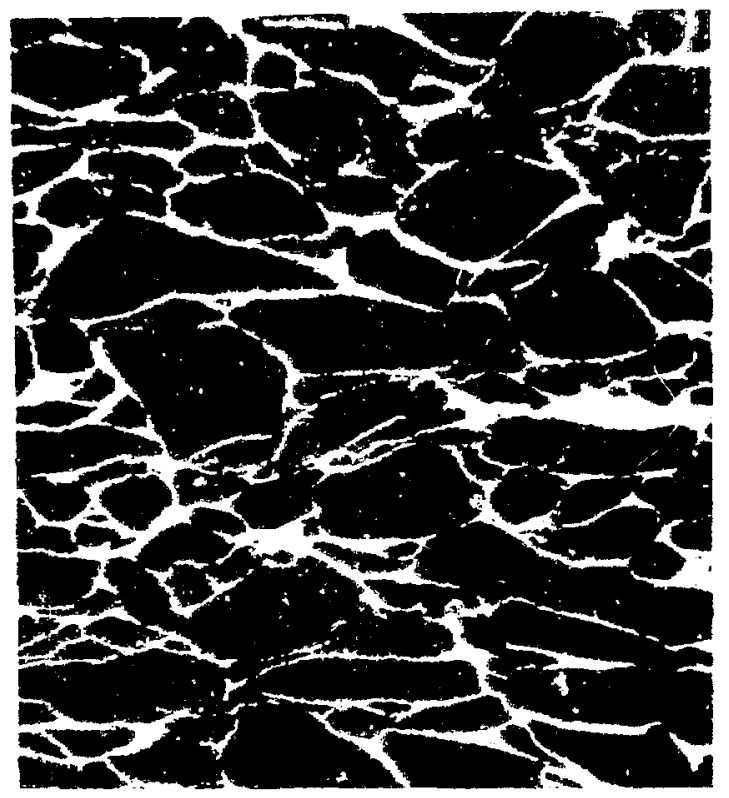

$|100 \mu|$

b) PIC-19 microstructure.

Fig. 5. Macrostructure and microstructure of a PIC-19 pellet. Pressing pressure was directed from top and bottom toward center of specimen.

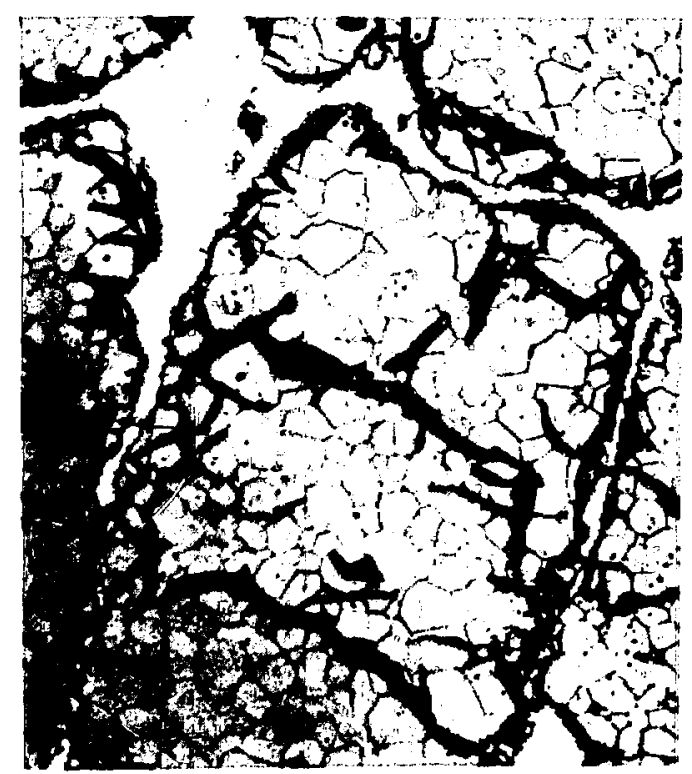

$|20 \mu|$

a) As pressed PIC-4

As Etched

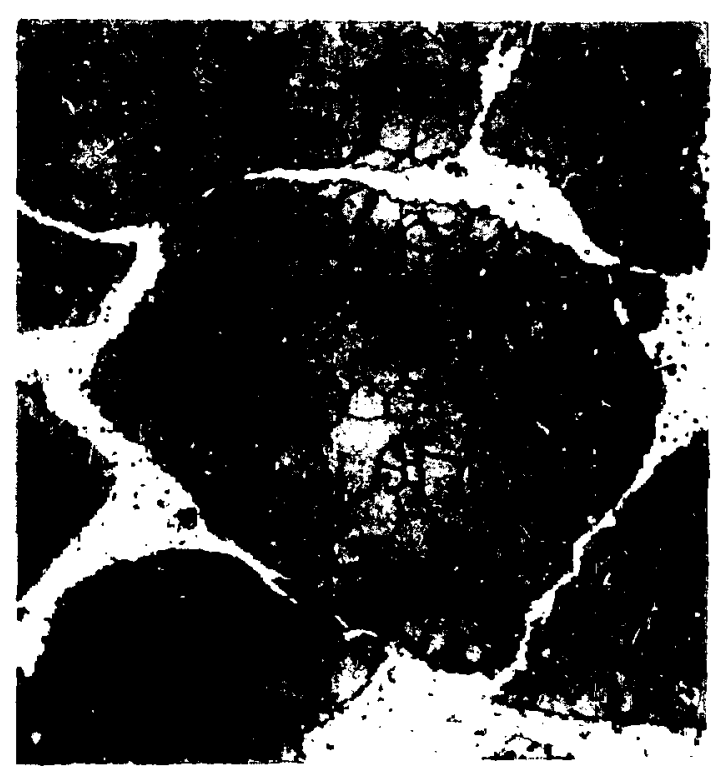

$|20 \mu|$

b) Heat treated PIC-4 HT

Fig. 6. PIC-4 microstructure, (a) as-hot pressed at $1520^{\circ} \mathrm{C}$, and (b) after heat treatment in air $/ 1100^{\circ} \mathrm{C} / 41 \mathrm{hr}$. 


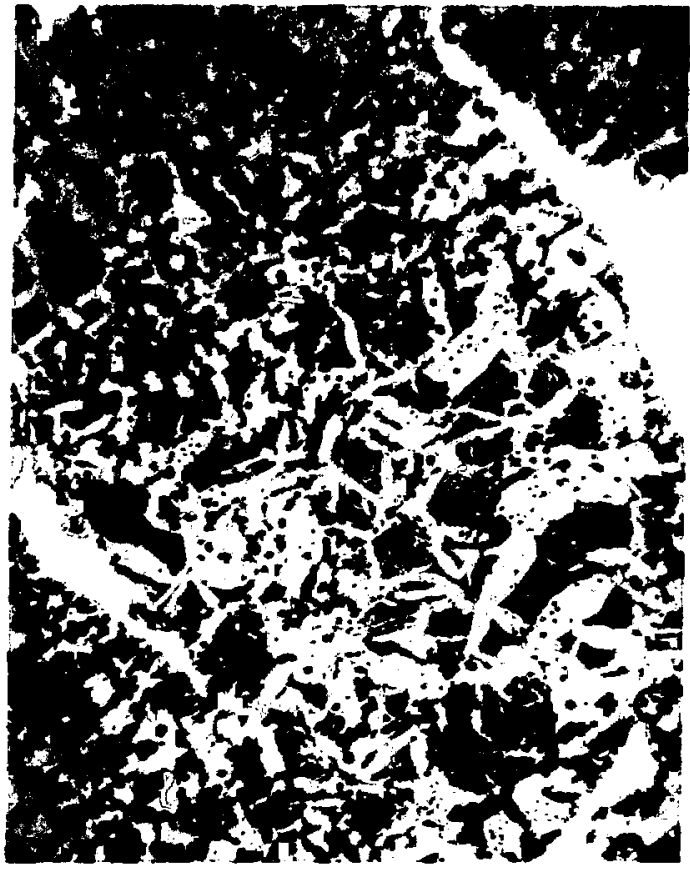

$|20 \mu|$

a) As pressed PIC-3 .

As Etched

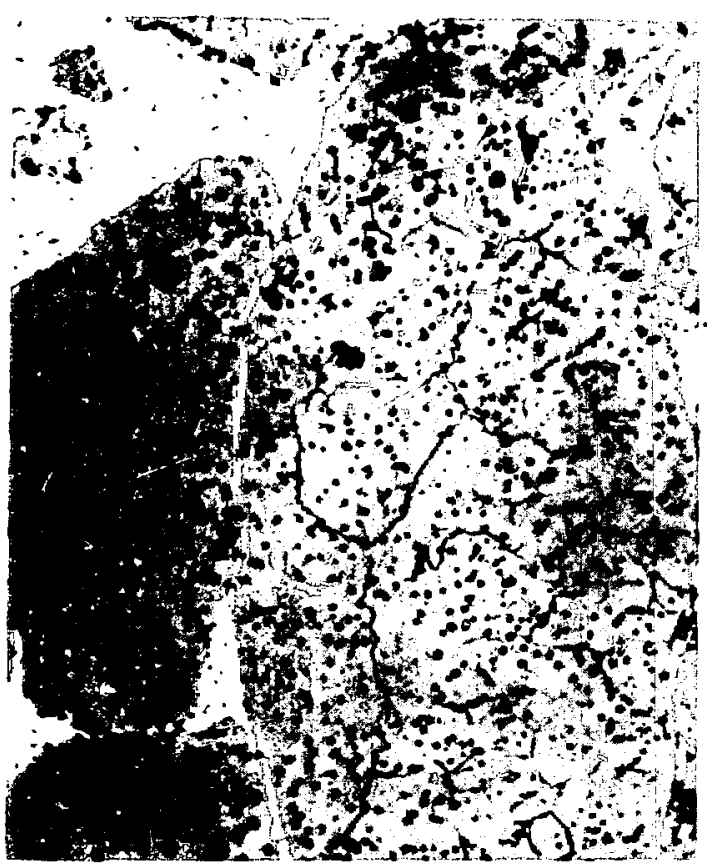

$20 u$

As Etched

b) Heat treated PIC-3 HT

Fig. 7. PIC-3 microstructures (a) as pressed at $1600^{\circ} \mathrm{C}$, and (b) after heat treatment in air $/ 1100^{\circ} \mathrm{C} / 41 \mathrm{~h}$.

TABLE VI

PIC PELLET HEAT TREATMENT DATA

\begin{tabular}{|c|c|c|c|c|c|c|c|c|c|}
\hline PIC No. & $\begin{array}{l}\text { Temp } \\
\text { (C) }\end{array}$ & $\begin{array}{l}\text { Time } \\
\text { (hr) }\end{array}$ & Atmosphere & $\begin{array}{l}\Delta \text { Weight } \\
(\%)\end{array}$ & $\begin{array}{l}\Delta \text { Length } \\
(\%) \\
\end{array}$ & $\begin{array}{l}\Delta \text { Diam } \\
(\%) \\
\end{array}$ & $\begin{array}{l}\Delta \text { Volume } \\
(\%) \\
\end{array}$ & $\begin{array}{c}\Delta \text { Density } \\
(*) \\
\end{array}$ & Comments \\
\hline 3 HT & 1100 & 41 & Air & -0.46 & -0.47 & $\mathbf{0}$ & -0.47 & Increase & $\begin{array}{l}\text { Substoichiometric oxide } \\
\text { was reoxidized }\end{array}$ \\
\hline 4 HT & 1100 & 41 & Air & -0.59 & -0.15 & 0 & -0.15 & Decrease & $\begin{array}{l}\text { Substoichiometric oxide } \\
\text { was reoxidized }\end{array}$ \\
\hline 5 HT & 1075 & 2 & $\mathrm{CO}_{2}$ & +0.14 & +0.72 & 0 & +0.72 & Decrease & $\begin{array}{l}\text { Substoichiometric oxide } \\
\text { was reoxidized }\end{array}$ \\
\hline $2 \mathrm{HT}$ & 1370 & 6 & $\mathrm{Ar} / \mathrm{H}_{2}{ }^{16} \mathrm{O}$ & +0.43 & -0.36 & -0.50 & -1.35 & Increase & $\begin{array}{l}\text { No change in surface } \\
\text { appearance }\end{array}$ \\
\hline 13 HT & 1200 & 36 & Afr & -0.60 & -0.28 & -0.54 & -1.36 & Increase & $\begin{array}{l}\text { Light brown discolor- } \\
\text { ation on surface }\end{array}$ \\
\hline $14 \mathrm{HT}$ & 1300 & 36 & Air & -1.16 & -0.45 & -0.66 & -1.77 & Increase & $\begin{array}{l}\text { Darker brown dis- } \\
\text { coloration on surface }\end{array}$ \\
\hline $22 \mathrm{HT}$ & 1440 & 12 & $\mathrm{Ar} / \mathrm{H}_{2}{ }^{16} \mathrm{O}$ & +1.81 & +0.39 & +0.60 & +1.58 & Decrease & Slightly dulled surface \\
\hline $2 \mathrm{HT}$ & 1440 & 12 & $\mathrm{Ar} / \mathrm{H}_{2}{ }^{16} \mathrm{O}$ & +2.58 & +4.19 & +0.66 & $\therefore 2.19$ & Decrease & Slightly dulled surface \\
\hline $2 \mathrm{HT}$ & 1440 & 12 & $\mathrm{Ar} / \mathrm{H}_{2}{ }^{16} \mathrm{O}$ & 1.97 & +1.17 & +1.73 & +2.95 & Decrease & Slightly dulled surface \\
\hline
\end{tabular}

*Calculated from pellet dimensions and welghts. 


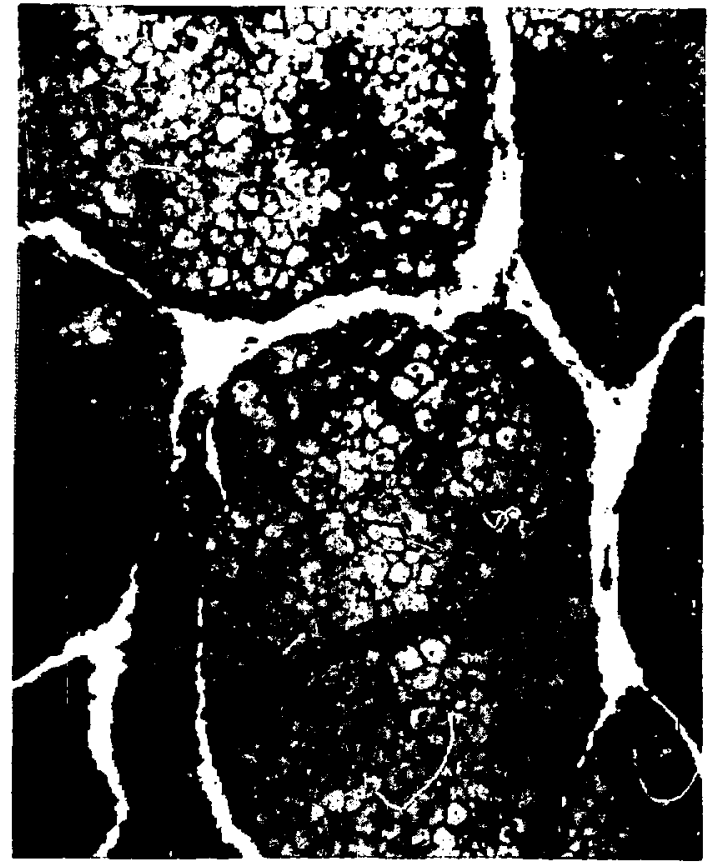

$20 \mu$
As Etched

a) As pressed PIC-5.

Fig. 8. PIC-5 microstructure (a) as-pressed at $1500^{\circ} \mathrm{C}$,

was not as dense initially as the pellet PIC $-4 \mathrm{HT}$ (87\% T.D. v8. $93 \%$ T. D., respectively).

Pellet PIC-5 was heat treated in $\mathrm{CO}_{2}$ at $1075^{\circ} \mathrm{C}$ for 2 hours to determine the extent of reoxddation. As shown in Fig. 8, complete reoxidation took place even after this relatively mili heat treatment. Table VI shows the corresponding dimensional change. The specimen did undergo a weight gain and increased in length causing an overall volume increase and corresponding decrease in density. The volume increase may be due to cracking of the specimen as seen in Fig. 8b.

In addition to air and $\mathrm{CO}_{2}$, an $\mathrm{Ar} / \mathrm{H}_{2}{ }^{16} \mathrm{O}$ atmosphere was used to heat treat a few pellets. This atmosphere should adjust the stoichlometry of the oxdide with no Ir reaction. This treatment was successful as the photomicrographs displayed in Fig. 9 show. The microstructure following this heat treatment was free of substoichiometric oxdde and was simllar in appearance to

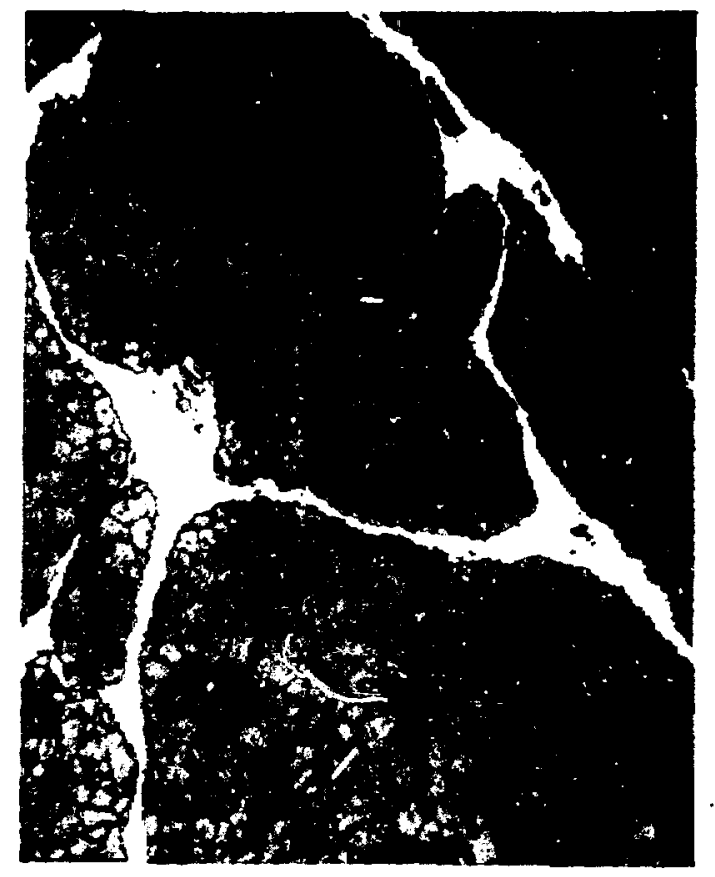

$\mathbf{2 0} \mu$

Ae Etched

b) Heat treated PIC-5HT. the microstructures of pellets heated in air (at $1100^{\circ} \mathrm{C}$ ) or $\mathrm{CO}_{2}$ (Figs. $7 \mathrm{~b}$ and $8 \mathrm{~b}$ ). As shown in Table $\mathrm{VL}$, the PIC-12HT pellet Increased In weight and apparent density. These pellete were highly dense (96\% T. D.) as pressed, however, and any cracks formed in these pellets, which would tend to increase the dimensions, would not be compensated for by sintering shrinkage.

Although the pellets which had been heat treated in air at $1100^{\circ} \mathrm{C}$ did not show a visible iridium loss, they did exhibit some weight decrease. To explore this reaction further at higher temperatures, pellet PIC-13 was heated at $1200^{\circ} \mathrm{C}$ in air, and pellet PIC-14 was heat treated at $1300^{\circ} \mathrm{C}$ in alr. The results are summarized in Table VI. The pellets lost weight with increasing temperature. The apparent density of each pollet increased due to volume shrinkage. The surfaces of the pellets were discolored. Ceramographic examination of the pellets revealed that the Iridium was unaffected 


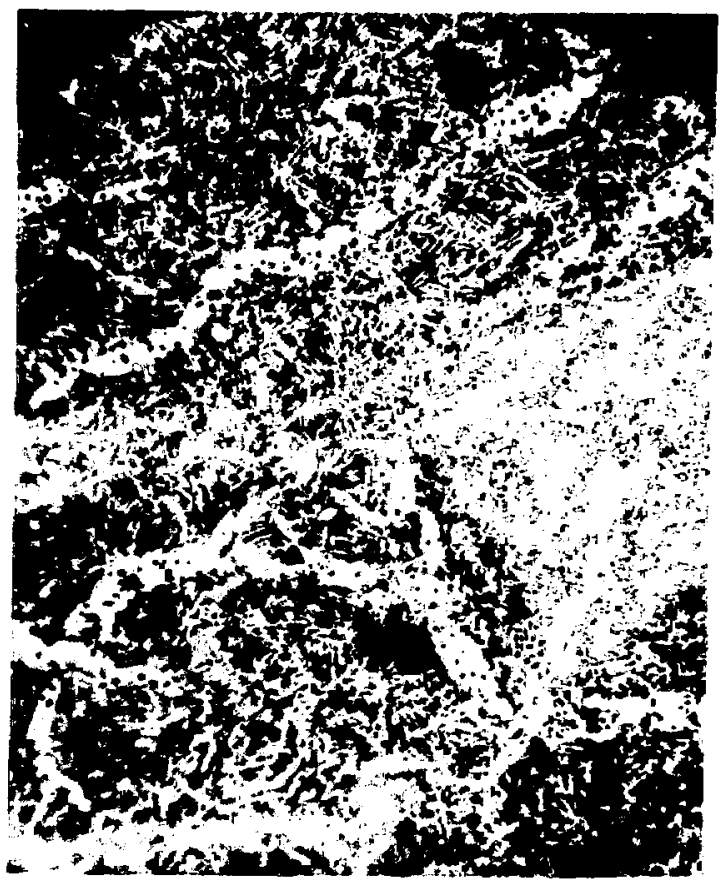

$|20 \mu|$

a) As pressed PIC-12

Fig. 9. PIC-12 microstructure, (a) as pressed at $1600^{\circ} \mathrm{C}$

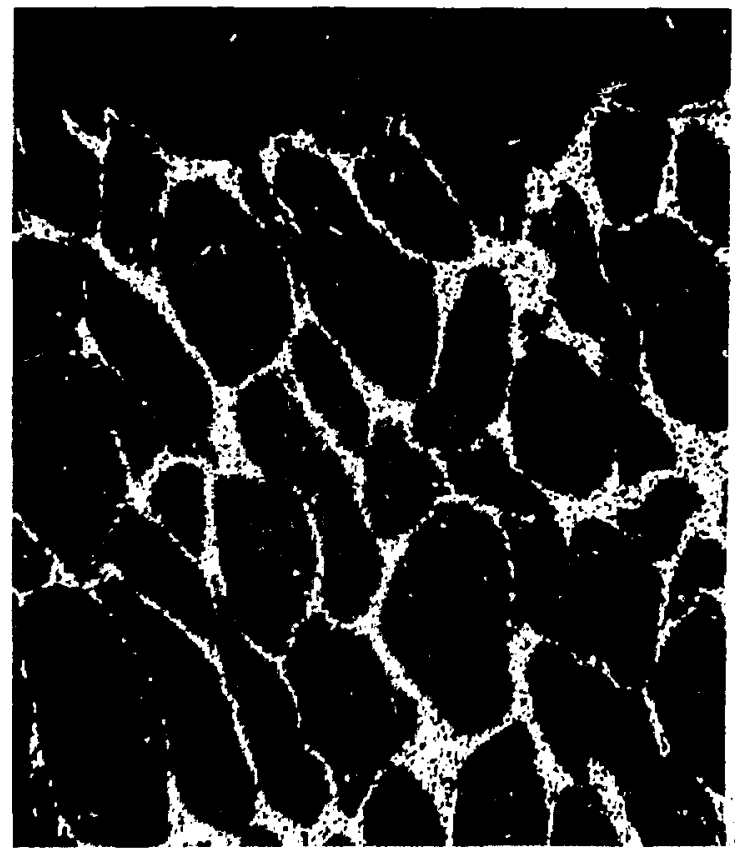

$\mid \overline{100 \mu \mid}$

As Pollshed

Fig. 10. PIC-14HT heat treated in air $/ 1300^{\circ} \mathrm{C} / 36 \mathrm{~h} \mathrm{--}$ note Ir loss near surface of pellet.

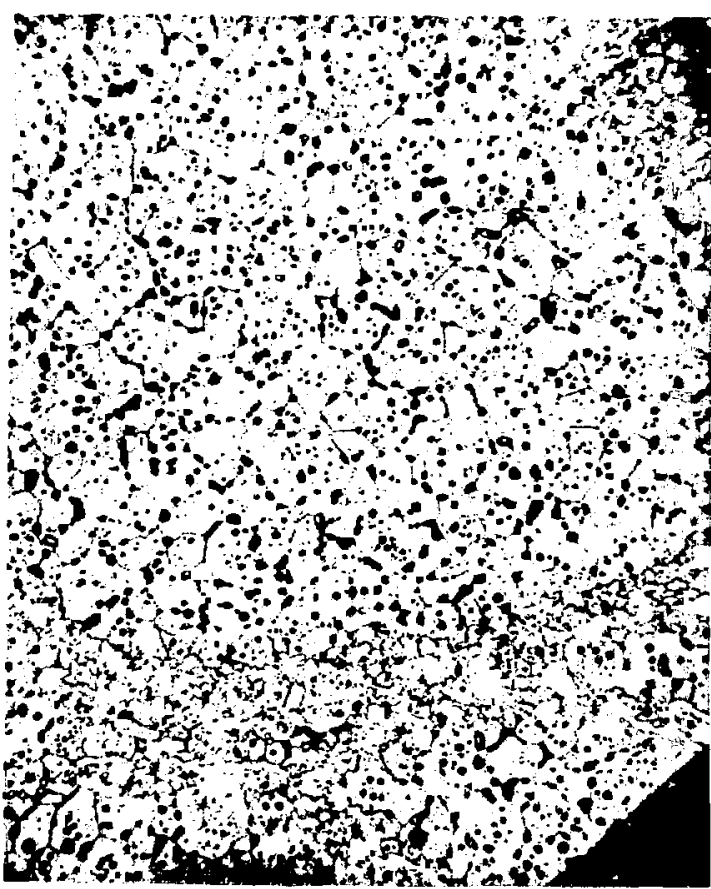

$|20 \mu|$

As Etched

b) Heat treated PIC-12 HT.

(b) after heat treatment in $\mathrm{Ar}-\mathrm{H}_{2} \mathrm{O}^{16} / 1370^{\circ} \mathrm{C} / 6 \mathrm{~h}$.

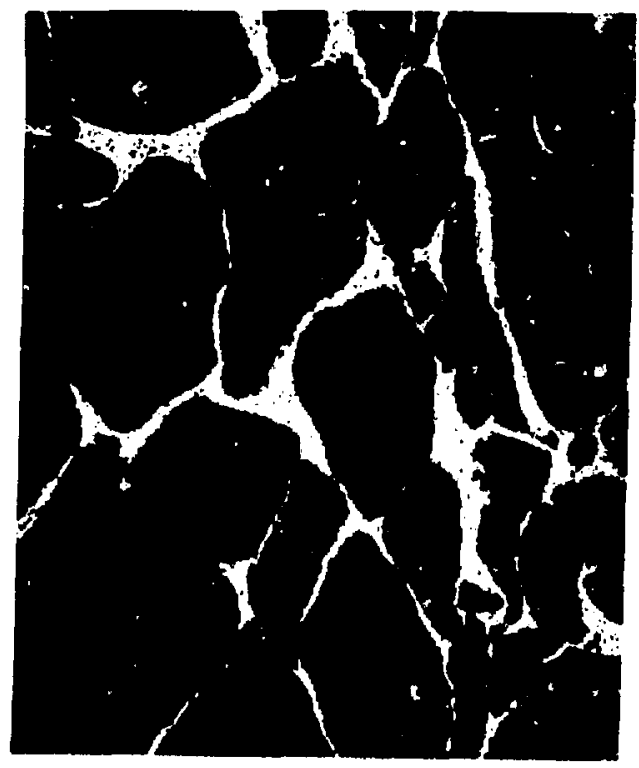

$|50 \mu|$

As Polishod

Fig. 11. PIC-20 microstructure as pressed -- fabrlcation analogous to PIC-21 sphere. 
TABI.E vI

DIBEXSIOXAL A.SD THERMAL DATA FOR PIC-21. 100 WATT SPIIEIKE

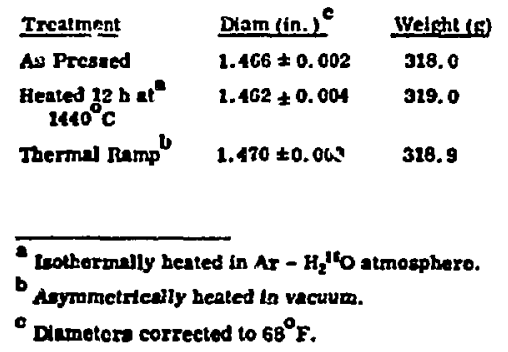

328.9

teolhermally heated in Ar - $\mathrm{H}_{2}{ }^{\mathrm{H}} \mathrm{O}$ atmosphero.

b Asymetriesily healed in vacuum.

c Dinmetere corrected to $68^{\circ} \mathrm{F}$.

in the pellet interiors, there was an observable Ir ios8 near the surfece. This is illugtrated in FIg. 10, a photomicrograph of the PIC-14HT pellet.

C. PIC Sphere

The PIC sphere (PIC-21) weight and dimensions as presied and after heat treatment are given in Table VI. The ophericity of the body was good as evidenced by the near identical diameter dimenstons measured in the polar and equatorial directions. The sphere gained $1 \mathrm{~g}$ in welght after being heated to $1440^{\circ} \mathrm{C}$ in $\mathrm{Ar}-\mathrm{H}_{2}{ }^{16} \mathrm{O}$ for 12 hours. The dimensional stabllity of the sphere is obvious from the tabulated data.

The ephere containod approximately $252.5 \mathrm{~g}$ of ${ }^{206} \mathrm{PuO}_{2}$ or 100 watts (t). Since the ophere was nominally 92\% T. D. and contained 12 vol. $\%$ Ir, the quantity of radioactive material per unit volume was essentially the aane as that for PPO spheres which currently are pressed to $80-82 \%$ T. D. There is no reduction in power density of PIC compared to PPO. An approximation of the ephere microstructure is given in Fig. 11, which shows the microgtructuze of the PIC-20 pellet. This pellet had been fabricated under conditions similar to those used for the ephere (aee section III-G).

The PIC gphere is shown in the as presed condition in Fig. 12. The sphere was free of cracks. A surface irregularity near the equator "bolly-band" was probably caused by partial break-down of the graphite punch knife edge during the hot prese run. This irregularity was relatively minor. It will be poseible to eliminate this problem in future runs by olightly recucing the maxdmum preasure and/or by applying the pressure

at a higlier temperature; e.g. at $1440^{\circ} \mathrm{C}$ instead of $1155^{\circ} \mathrm{C}$ as followed in PIC-21. At the higher temperature the charged material should be more plastic and yielding.

Eleven days after being hot pressed, the PIC sphere was subjected to a re-oxidation heat treatment by heating to $1440^{\circ} \mathrm{C}$ in $\mathrm{Ar}-\mathrm{H}_{2}{ }^{16} \mathrm{O}$ for 12 hours. The sphere was heated over 4 hrs, heid at $1440^{\circ} \mathrm{C}$ for 12 hrs, and subsequently cooled over 5 hours. The sphere had gained $1 \mathrm{~g}$ in weight in the 11 day interval between hot pressing and heat treatment, indicating it had undergone some self-adjustment in stoichiorietry. This is not surprising because of the low (but finite) amounts of $\mathrm{H}_{2} \mathrm{O} / \mathrm{O}_{2}(\sim 100 \mathrm{ppm})$ in the inert gloveboxes. During the heat treatment one crack formed on one polar surface. hereafter referred to as the "south" pole. The remainder of the sphere was unaffected as shown in Fig. 13.

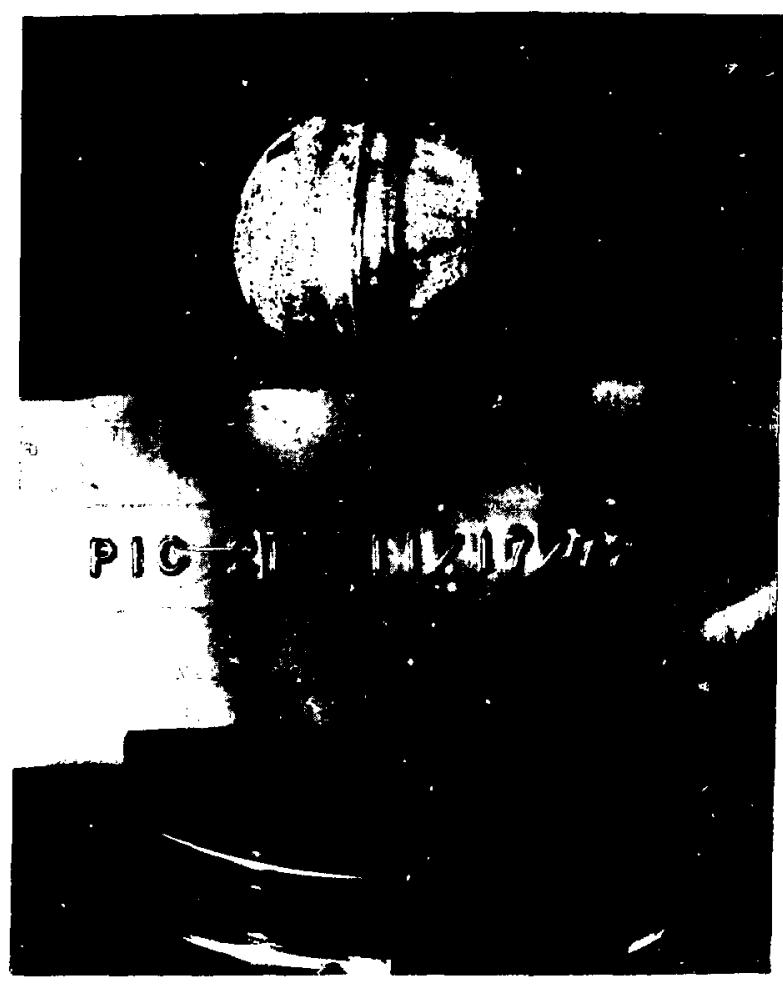

Fig. 12. PIC-ophere in as-pressed condition. 

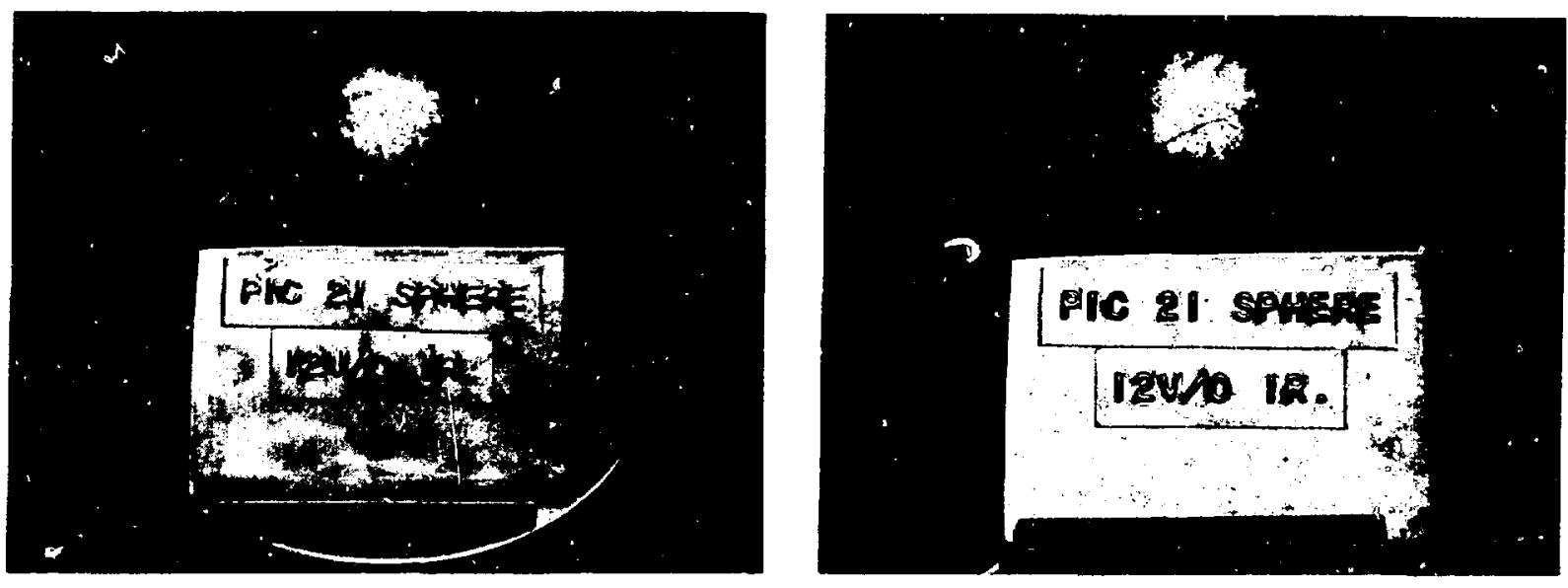

Fig. 13. PIC sphere after heat-treatment at $1440^{\circ} \mathrm{C}$ for $12 \mathrm{hr}$ in $\mathrm{Ar}-\mathrm{H}_{2}{ }^{16} \mathrm{O}$.

(a). North pole.

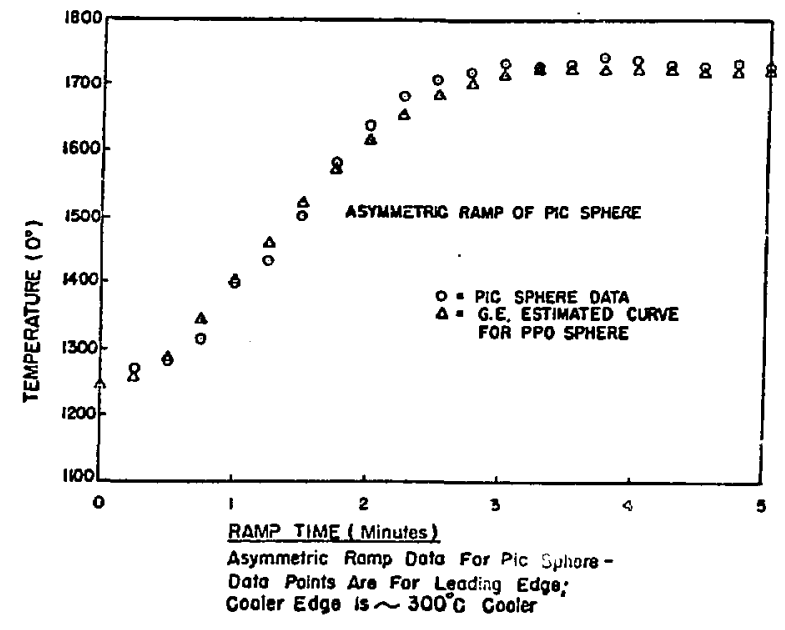

Fig. 14. Asymmetric ramp of PIC-21 sphere.

\section{ASYMMETRICAL THERMAL RAMP OF PIC SPHERE}

A. Ramp Experimental

As part of qualificatim ¿of PPO spheres,

they are subjected to an asymmetricthermal ramp over a short ( $50 \mathrm{~min}$ ) time. Temperature differentials are chosen to simulate "worst-case" re-entry conditions with the sphere leading edge at near $1750^{\circ} \mathrm{C}$ and the trailing edge $\sim 300^{\circ} \mathrm{C}$ cooler. A more stringent parameter is (b). South pole

time since these conditions are attained within $<5 \mathrm{~min}$. To establish some basis for comparison, the PIC sphere was subjected to the same ramp.

The most critical portion of the ramp schedule is shown in Fig. 14. The temperatures shown are on the hotter edge. The temperature increases almost $500^{\circ} \mathrm{C}$ degrees in 3 iminutes. The experimental curve for the PIC sphere closely approximated the predicted re-entry values. Prior to the ramp, the sphere was heated to $1247^{\circ} \mathrm{C}$ in $21 / 2$ hours, ramped, and cooled from $1728^{\circ} \mathrm{C}$ to about $700^{\circ} \mathrm{C}$ in approximately $35 \mathrm{~min}-$ utes.

A schematic diagram of the susceptor used for the asymmetric ramp is shown in Fig. 15. This particular susceptor design was developed as a result of tests conducted on thoria simulant spheres. These tests were carried out in a cold apparatus in a separate facility with quite elaborate instxumentation to ensure that the proper temperature differential across the diameter was established. A similar susceptor, coil, and MG set were used for the actual PIC sphere ramp although the glovebox operation requirement prohibited installation of all analogous instrumentation. However, use of available temperature recording devices in addition to matching control settings allowed the ramp to be completed with acceptable accurucy. 


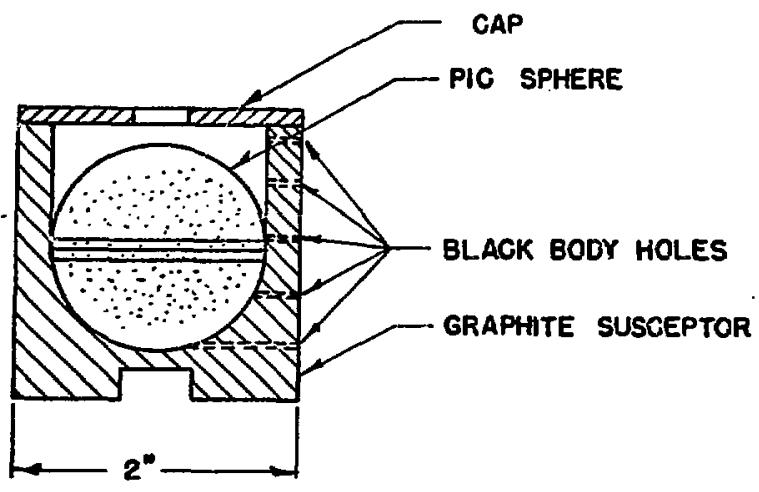

Fig. 15 Schematic diagram of asymmetric ramp susceptor.
The post-ramped ephere is shown in Fig. 16.

The north pole remained crack free. The thin crack on the south pole was extended to the equatorial belly-band and ran alongaide the belly-band but did not cross it. Otherwise the ephere was unaffected by the ramp, as llustrated by the weight and dimenglonal data provided in Table VII.

\section{B. Theoretical Considerations}

A PIC ephere should have increased thermal shock zesiatance to PPO for two reasons: (1) the thermal conductivity of the body is higher as a result of the motal phase, (2) at elevated temperatures the metal should be relatively plastic and would tend to absorb the energy of a proyagating crack, thereby arresting signiflcant crack elongation and epreading. Hasselman ${ }^{5}$ showed that the optimum value of strength (for resistance to thermal alock) for a ephere is given by:

$$
g_{t}=1 / 2 \frac{7 N E y_{\text {eff }}}{2(1-v) b}
$$

where $S_{t}$ is the tensile strength, $v$ is Polssons' ratio,

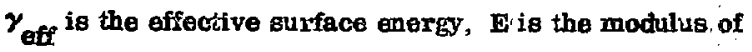
elasticity, $b$ is the sphere diameter, and $\mathrm{N}$ is the number of cresks. Incorporaring a relatively ductile metallic phase in the ceramic $\mathrm{PuO}_{2}$ matrix raises the $\gamma_{\theta f f}$ and hence zaises the optimum strength value.

Altennatively, a meagure of the thermal stress resistance of a sphere can be obtained by equating the total suriace energy required for the propagation of the cracks to the elastic energy stored at frecture. For this case the mean area (A) over which (N) numb will propagate in a sphere is given by:

$$
A=\frac{2 n S_{t}^{2}(1-v) b^{3}}{\text { TNE } \gamma_{\text {off }}}
$$

If the calculated area (A) for a given material and ephere gize is greater thas the cross-sectional area of the ephere $\left(\pi b^{2}\right)$, tha cracks will completely traverse the body and lead to fallura, but if (A) is smaller than the crosesectional area of the ephere, the crack will be arregted and the ephere will remain intact.

Most of the parameters in equations 1 and 2 are readily maagured by standard laboratory methods. The effective eurface energy can be meneured by the 80-called work-of-fracture test which has recently ${ }^{6,7}$ seen increaging popularity because of the importance of fracture Buriace energy as a dasign parameter for cermic materfals. This parameter bas been related to thermal shock registance through stroin-energy criterie $5,8,9$ and to strength vis the Grfffity-Orown ralution ${ }^{10-12}$ and can be related to microstructural variatlons through electromicrography. When properties such as elagtic modulue, tentlle strength, etc. have been dotermined, It will be poseible to use the SE date in the above equam tions to arsive at a valld "Ilgure-of-maxt" evaluation for all types of ceramle fuels.

\section{DLAMZTRAL COMPIESSION TESTS Some of the PIC opecimens (reanl that ench "run" yielded three liential pellete) were used to ob- tain diaraetral compresaion date. This test his beon}




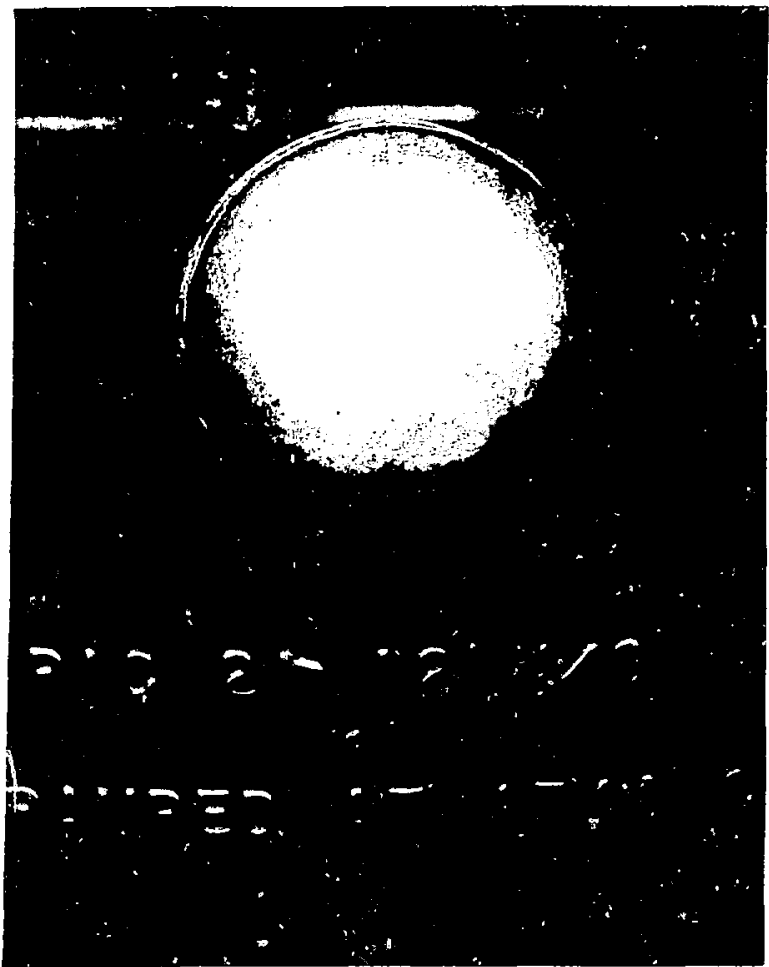

South Pols

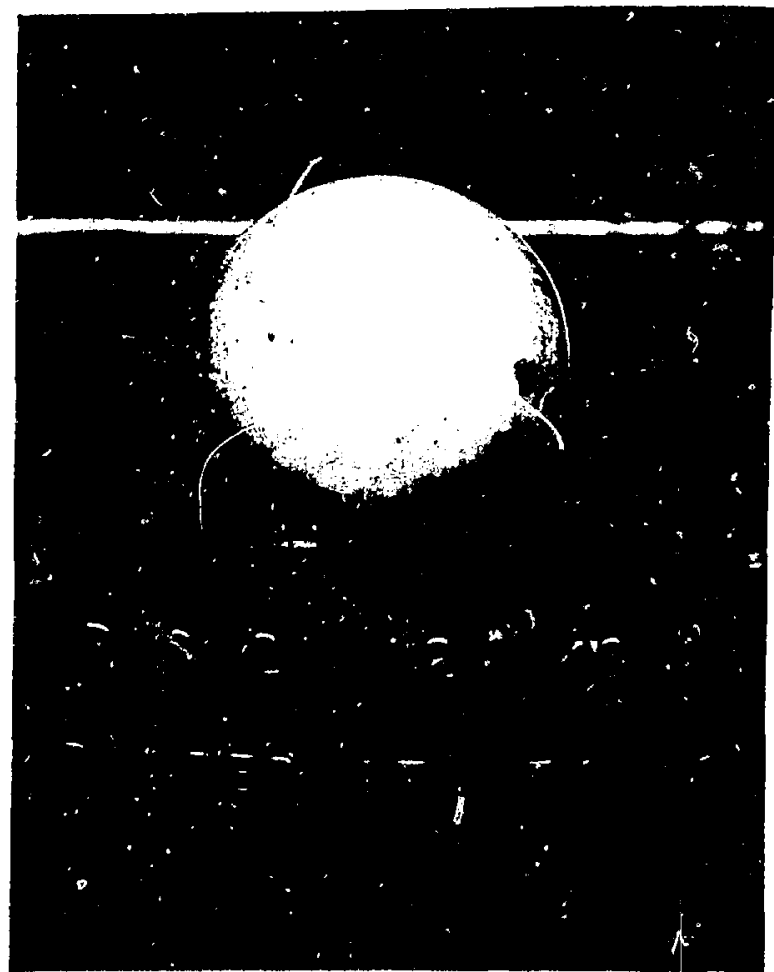

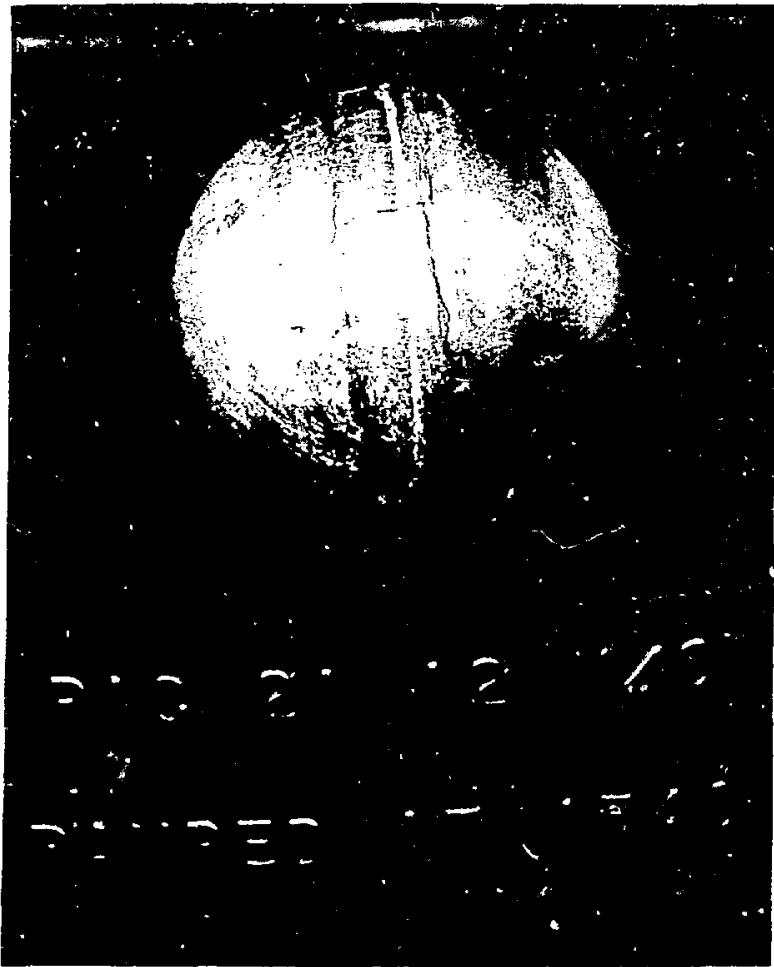

Fig. 16. PIC sphere appearance after asymmetric ramp.

used and described by Rankin, ${ }^{13}$ and Rudnick ${ }^{14}$ in studies on $\mathrm{Al}_{2} \mathrm{O}_{3}$-Mo composites, a system reasonably analogous to $\mathrm{PuO}_{2}$-Ir. In this test, right cylindrical specimens are loaded laterally in compression, but according to elastic theory, a biaxial stress distribution is produced within the specimen so that a tensile stress is developed at right angles to the diameter (and to the compressive stress). The specimen actually fails in tension, with the maximum tensile stress easily computed from

$$
\sigma=\frac{2 \mathrm{P}}{\pi \mathrm{Dt}}
$$

where $\sigma$ is the maximum tensile stress $P$ is the applied load, $\mathrm{D}$ is the specimen diameter and $\mathrm{t}$ is the specimen thickness.

Accordingly, a series of PIC pellet specimens nominally 0.3 in. long by $0.3 \mathrm{in}$, diameter were mechanically tested at room temperature. Specimens (with 
TABSI,E VII

PIC Pellet Strength Data

\begin{tabular}{|c|c|c|c|c|}
\hline $\begin{array}{c}\text { PIC } \\
\text { Spec. No. }\end{array}$ & $\underset{\text { (psi) }}{\sigma_{\max }}$ & $\begin{array}{c}E \\
\text { psi } \times 10^{6}\end{array}$ & $\begin{array}{c}\frac{7}{0} \\
\mathrm{~T} . \mathrm{D} .\end{array}$ & $\begin{array}{c}s_{0} \\
\text { (psi) }\end{array}$ \\
\hline 2 & 5300 & - & 81 & 20,600 \\
\hline 6 & 9300 & 3.0 & 92 & 16,000 \\
\hline 9 & 6700 & - & 92 & 11,500 \\
\hline $11 \alpha$ & 8900 & 5.4 & 89 & 19,100 \\
\hline $11 \beta$ & 9800 & 5.3 & 89 & 20,500 \\
\hline 12 & 5900 & 6.6 & 90 & 11,900 \\
\hline 13 & $-\infty$ & 8.0 & 84 & -- \\
\hline 14 & 3800 & 5.3 & 87 & 9,500 \\
\hline $15 \alpha$ & 9300 & 3.0 & 93 & 15,300 \\
\hline $15 \beta$ & 9000 & 3.7 & 93 & 14,400 \\
\hline $16 \alpha$ & 5400 & -- & 93 & 8.200 \\
\hline $16 \beta$ & 9300 & 5.5 & 92 & 16,500 \\
\hline 17 & 9100 & 7.6 & 91 & 16,600 \\
\hline $19 \alpha$ & 16,900 & -- & 97 & 21,400 \\
\hline $19 \beta$ & 15,200 & -- & 96 & 20,400 \\
\hline $22 \alpha$ & -- & 7.0 & 95 & -- \\
\hline $22 \beta$ & 3900 & -- & 96 & -- \\
\hline $22 \gamma$ & 2900 & - & 92 & - \\
\hline
\end{tabular}

ends flat and parallel to within \pm 0.005 in.) were first loaded axially in compression to obtain data for the determination of Youngts modulus. The specimens were loaded in a device fitted with tungsten carbide platens and mounted in an Instron within a glovebox. The load was measured with an Ingtron compression load cell. The diametral compression test was performed using a crosshead speed of $0.05 \mathrm{in} . / \mathrm{min}$.

Compressive load-deflection data were obtained from eleven specimens. The deflection data were obtained with an IVDT deflectometer. It was necessary to correct these data for subpress deflection. Each specimen compression tested was loaded to 500 pounds twice to insure complete seating on the load platens. None of the specimens failed at this load, and by comparison with specimens which were tested in diametral compression only, the axial compression loading did not affect the subsequent diametral tests.

\section{Diametral compression test data were obtained}

from 16 specimens. For these tests the specimens were each locsely wrapped in heavy aluminum foil. The foll contained the pellet fragments after failure and provided a pad between the load platen and the specimen. This padding is required to avoid high shear stresses immediately under the points ố lnading. All the specimens failed in either the double or triple cleft modes. The double cleft is the normal tensile failure down the loaded diameter, whereas the triple cleft is a normal tensile failure in which the pellet breaks along the loaded diameter and opposite sides of and parallel to this cleavage. Double and triple cleft failures are evidence that the specimen definitely failed in tension rather than shear and that equation 3 is applicable.

The strength data are tabulated in Table VIII. The tensile strength at zero porosity. $S_{0}$, was encapsulated from the Knudsen ${ }^{15}$ equation, $S=S_{0} e^{-b P}$. To determine the constant, " $b$ ", $s_{0}(\sigma \max )$ was plotted versus porosity ( $P$ ) on a semi-logarithmic basis, and neglecting the lowest strength values (anomalies due to surface irregularities and internal flaws) a value of $\sim 7$ was determined. In an analogous way Young's modulus could be modified for porosity using an equation of the form $E=E_{o}(1-k P)$. The method used to determine the elastic modulus was too inexact, however, to warrant this treatment.

Some general observations can be drawn from these strength data. Although the tensile strength values varied from 2,900 to $16,900 \mathrm{psi}$, this is not surprising in view of the variation in Ir content, age, $\mathrm{PuO}_{2}$ granule size distribution, firing temperature porosity, stoichiometry, and hot pressing parameters. There are not enough data to permit assignment of relative effects of all the processing variables on the mechanical properties. In fact, since the strength of brittle materials must be described statistically, the values listed in Table VII should be regarded only as trends. It is apparent, however, that the pellets PIC-19 had significantly higher strengths than any of the others. These pellets had been prepared from fresh feed, prefired into granules at a relatively low temperature $\left(1075^{\circ} \mathrm{C}\right)$ to retain as much sinterability as possible. They are pressed at high pressure (10,000 psi) to a high density (96\% T. D.). From Fig. 5, the $\mathrm{PuO}_{2}$ granules exhibit evidence of 
plastic flow and distortion. Since none of the other pellet microstructures or strengths resembled PIC-19, the processing parameters should be re-examined more thoroughly. The PIC-22 pellets (prepared in a way similar to PIC-19) had very low strengths. These pellets, it should be remembered, were heat treated at $1440^{\circ} \mathrm{C}$ for 12 hours in $\mathrm{Ar}-\mathrm{H}_{2}{ }^{16} \mathrm{O}$. It is possible that this post-press heat treatment produced cracks within the pellets which lowered their strength. The diametral compression strength test is well suited to quantify the effect of various post-press thermal equilibrations. When corrected for porosity, the strength values $\left(S_{O}\right)$ approached 20,000 to $21,000 \mathrm{psi}$. The ultimate strength of a "refined" PIC material should be significantly higher.

\section{SUMMARY}

Plutonia-iridium cermets were prepared by a multi-step method involving the formation of pre-fired $\mathrm{PuO}_{2}$ granules, coating of these relatively large granules with iridium powder particles, and subsequent hot pressing of the mixture. While further studies are required, at present the optimum prefiring temperature for providing sinterable $\mathrm{PuO}_{2}$ granules with sufficient strength and cohesiveness appears to be $\sim 1075^{\circ} \mathrm{C}$. The amount of plutonium dloxide reduction increased with increasing hot pressing temperature and time, becoming extensive at temperatures near $1600^{\circ} \mathrm{C}$. The stoichiometry of the specimens could be adjusted by subsequent heat treatment without adversely affecting the iridium.

A 100-watt, $\sim 1.470$ in. diameter, PIC sphere was made. As hot pressed, the sphere was crack-free and was approximately $91.5 \%$ dense. Since the sphere contained 12 vol \% iridium, the power density (watts $/ \mathrm{cm}^{3}$ ) was essentially equal to that of the PPO apheres currently under study. The PIC sphere survived subsequent heat treatment and asymmetric ramp tests very satisfactorily.

Diametral compression tests performed on some of the PIC pellets indicated differences in strength which could be attributed to processing procedures. This type of measurement shows good promise as a process development tool.

\section{ACKNOWLEDGEMENTS}

The authors are indebted to C. L. Gilley for aid in the specimen preparation; to C.C. Land for the photomicroscopy; to L. B. Lundberg for the mechanical property measurements, and to G. R. Waterbury and the analytical group for chemical analyses.

\section{REFEREINCES}

1. M. W. Shupe, LASL, Informal Trip Report, General Electric Co. : Fvandale, Ohio, May 21, 1971.

2. C. B. Alcock and G. W. Hooper "Thermodynamics of the Gaseous Oxides of the PlatinumGroup Metals," Proc. Roy. Soc. A, 254, 551$561(1960)$.

3. H. Schafer and N. J. Heitland, "Equilibrium Measurements in the System Iridium-Oxygen: Gaseous Iridium Trioxide," Zeitsch Anorg Chemie. 304, 249 - 265 (1960)

4. W. L. Phillips, Jr., "Oxidation of the Platinum Metals in Air," Trans, ASM, 57, 33-57 (1964).

5. D. P.H. Hasselman, "Elastic Energy at Fracture and Surface Energy as Design Criteria for Thermal shock," J. Amer. Ceram. Soc. 46 (11) $535-40(1963)$.

6. J. A. Copolla and R. C. Brandt, "Measurement of Fracture Surface Energy of SiC, "J. Amer. Ceram. Soc., 55 (9) 455-560 (1972).

7. J.A. Copolla, R. C. Bradt, D. W. Richerson, and R. A. Alliegro, "Fracture Energy of Silicon Nitrides," Ceram. Bull, 51 (11) 847-851 (1972).

8. F. J. P. Clarke, H. G. Tattersall, and G. Tappin, "Toughness of Ceramics and Their Work of Fracture," Proc. Brit. Ceram. Soc. (6) 163172 (1966).

9. R. W. Davidge and G. Tappin, "Bffective Surface Energy of Brittle Materials," J. Mater. Sci. 3 (2) $165-73$ (1968)

10. J. A. Copolla and R. C. Braolt, "Fracture Energy of sllicon Carbide from $-195.8^{\circ} \mathrm{C}$ to $1500^{\circ} \mathrm{C}$." Proc. Int. Conf. Mech. Behavior Matter, Kyoto, Japan, Aug, 1971.

11. A. A. Griffith, "Phenomena of Fupture and Flow in Solids," Phil Trans. Roy. Soc. London, Ser A. 221, 163-98 (1920). 
12. F. F. Lange, "Fracture Energy and Strength Behavior of a Sodium Borosiliate Glass - $\mathrm{Al}_{2} \mathrm{O}_{3}$ Composite System," J. Amer. Ceram. Soc., 52 (2) 99-105 (1971).

13. D. T. Rankin, J. J. Stiglich, D. R. Petrik, and Robert Ruh, "Hot Pressing and Mechanical Properties of $\mathrm{Al}_{2} \mathrm{O}_{3}$ with an Mo-Dispersed Phase," J. Amer. Ceram. Soc., 54 (6) 277-281 (1971).
14. A. Rudnick, A. R. Hunter, and F. C. Holden, "Analysis of the Diametral-Compression Test," Mater. Res. Stand. 3(4) 283-89 (1963).

15. 5. P. Knudsen, "Dependence of Mechanical Strength of Brittle Polycrystallino Specimens on Porosity and Grain Size," J. Amer. Ceram. Soc. 42 (8) 376-87 (1959). 